\title{
Flow accelerated corrosion and erosion-corrosion behavior of marine carbon steel in natural seawater
}

\author{
Yunze Xu $\mathbb{D}^{1 凶}$, Qiliang Zhang $\mathbb{D}^{1}$, Qipiao Zhou ${ }^{1}$, Shan Gao $\mathbb{D}^{2,3 凶}$, Bin Wang ${ }^{3}$, Xiaona Wang ${ }^{4}$ and Yi Huang (iD ${ }^{1 凶}$
}

In this work, flow accelerated corrosion (FAC) and erosion-corrosion of marine carbon steel in natural seawater were electrochemically studied using a submerged impingement jet system. Results show that the formation of a relatively compact rust layer in flowing natural seawater would lead to the FAC pattern change from 'flow marks' to pits. The increase of the flow velocity was found to have a negligible influence on the FAC rate at velocities of $5-8 \mathrm{~m} \mathrm{~s}^{-1}$. The synergy of mechanical erosion and electrochemical corrosion is the main contributor to the total steel loss under erosion-corrosion. The increase of the sand impact energy could induce the pitting damage and accelerate the steel degradation. The accumulation of the rust inside the pits could facilitate the longitudinal growth of the pits, however, the accumulated rusts retard the erosion of the pit bottom. The erosion and corrosion could work together to cause the steel peeling at the pit boundary. The steel degradation would gradually change from corrosion-dominated to erosion-dominated along with the impact energy increasing.

npj Materials Degradation (2021)5:56; https://doi.org/10.1038/s41529-021-00205-1

\section{INTRODUCTION}

Carbon steels are extensively used in ocean engineering applications due to their low cost and high mechanical strength ${ }^{1-3}$. Because of the low contents of $\mathrm{Ni}$ and $\mathrm{Cr}$ elements, the passive film cannot form on the surface of carbon steel, leading to the steel degradation under active corrosion in seawater ${ }^{4,5}$. Seawater is always in motion due to the effects of tidal attraction, ocean current, and wind power. The contact between steel structures and moving seawater might induce flow accelerated corrosion (FAC) and erosion-corrosion ${ }^{6-9}$. Such issues are more obvious in high-speed vessels and underwater vehicles, where cruising speeds could reach above $10 \mathrm{~m} \mathrm{~s}^{-110-12}$.

Various studies were conducted in past decades to understand the main factors influencing the FAC in carbon steels ${ }^{13-18}$. It is generally found that the wall shear stress and the impact energy of fluids will increase with the flow velocity increasing, thus accelerating the removal of corrosion products ${ }^{17,18}$. Meanwhile, a higher flow velocity could enhance the mass transfer process ${ }^{9,18}$. Both factors facilitate the FAC process in the ocean. Accordingly, it is commonly thought that FAC in seawater is mostly controlled by the flow velocity ${ }^{19-21}$. A higher flow velocity leads to a more serious risk of $\mathrm{FAC}^{21}$. However, recent studies ${ }^{2,22}$ showed that apart from the flow velocity, the rust layer formed on the steel surface in natural seawater also played an important role on the FAC behaviour. Experimental results showed that the corrosion rate of the EH 36 carbon steel in flowing natural seawater was dramatically lower than that in the $3.5 \mathrm{wt} \% \mathrm{NaCl}$ solution at the same hydrodynamic condition ${ }^{2}$. Surface characterizations indicated that a more dense rust layer formed on the carbon steel in the flowing natural seawater than that in the flowing $3.5 \mathrm{wt} \% \mathrm{NaCl}$ solution, which effectively protected the steel from FAC. Furthermore, the relatively compact rust layer could only form in the natural seawater at a high flow velocity. The generated rust layer would become porous and lose its protective effect in stagnant seawater ${ }^{2,8}$. These findings suggest that the influence of the flow velocity on the FAC of carbon steels should be further studied in consideration of the corrosion product layer.

Since sand particles are always present in seawater, especially at the estuaries, the steel degradation induced by erosion-corrosion becomes another safety threaten of marine structures ${ }^{23-28}$. It is reported that the steel damage induced by erosion-corrosion is more serious than FAC due to the synergy of electrochemical corrosion and mechanical erosion ${ }^{29-32}$. The steel loss caused by erosion-corrosion could be several times higher than the summation of the steel loss induced by pure corrosion and pure erosion ${ }^{33,34}$. The impacts of sand particles on the steel surface could thoroughly remove the protective layer, cause the interfacial plastic deformation and facilitate the crack propagation, which would eventually enhance the corrosion process ${ }^{27}$. In turn, the corrosion could dissolve the work-hardened layer, accelerate the removal of embedded sand particles, and render the surface hardness degradation at anodic sites, which would enhance the erosion process ${ }^{35,36}$. Although the erosion-corrosion performances of carbon steels have been comprehensively studied, the erosion-corrosion experiments were mostly conducted in pure $\mathrm{NaCl}$ solutions or in simulated pipeline internal environment ${ }^{23,31,37}$. The symmetrical study of the erosion-corrosion in natural seawater is limited. As the FAC performance of carbon steels in pure $\mathrm{NaCl}$ solution is significantly different from that in natural seawater, the erosion-corrosion performance in natural seawater might be also different from that in pure $\mathrm{NaCl}$ solution or in artificial seawater. Moreover, most of the previous studies were focused on the general performances of the erosion enhanced corrosion and corrosion enhanced erosion. There are only a few reports on the interaction between the local sand impacts and the local anodic dissolution in pure $\mathrm{NaCl}$ solution ${ }^{25,26,38}$. The localized erosion-corrosion performance and the influences of the flow velocity on erosion-corrosion of carbon steels in natural seawater are still unclear.

\footnotetext{
${ }^{1}$ School of Naval Architecture and Ocean Engineering, Dalian University of Technology, Dalian 116024, China. ${ }^{2}$ Key Laboratory for Far-shore Wind Power Technology of Zhejiang Province, Hangzhou 311122, China. ${ }^{3}$ Powerchina Huadong Engineering Corporation Limited, Hangzhou 311122, China. ${ }^{4}$ School of Physic and Optoelectronic Engineering, Dalian University of Technology, Dalian 116024, China. ${ }^{凶}$ email: xuyunze123@163.com; gao_s3@ecidi.com; huangyi@dlut.edu.cn
} 

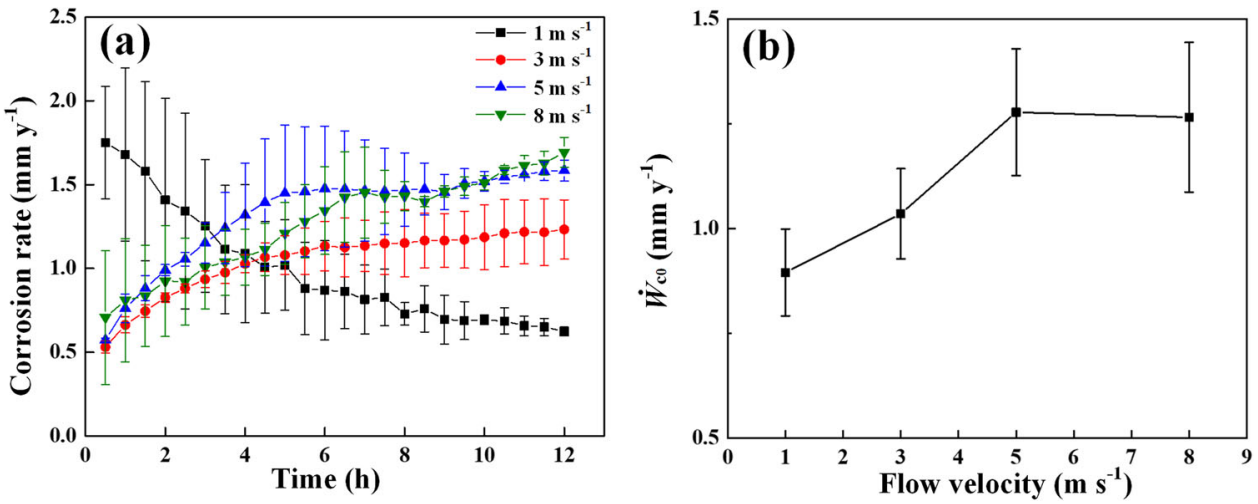

Fig. 1 Variation of corrosion rate in pure natural seawater. a Time dependence of the instant corrosion rates. $\mathbf{b}$ The general pure corrosion rate at different flow velocities. The error bars represent standard deviations of the three repeated tests at each flow velocity.

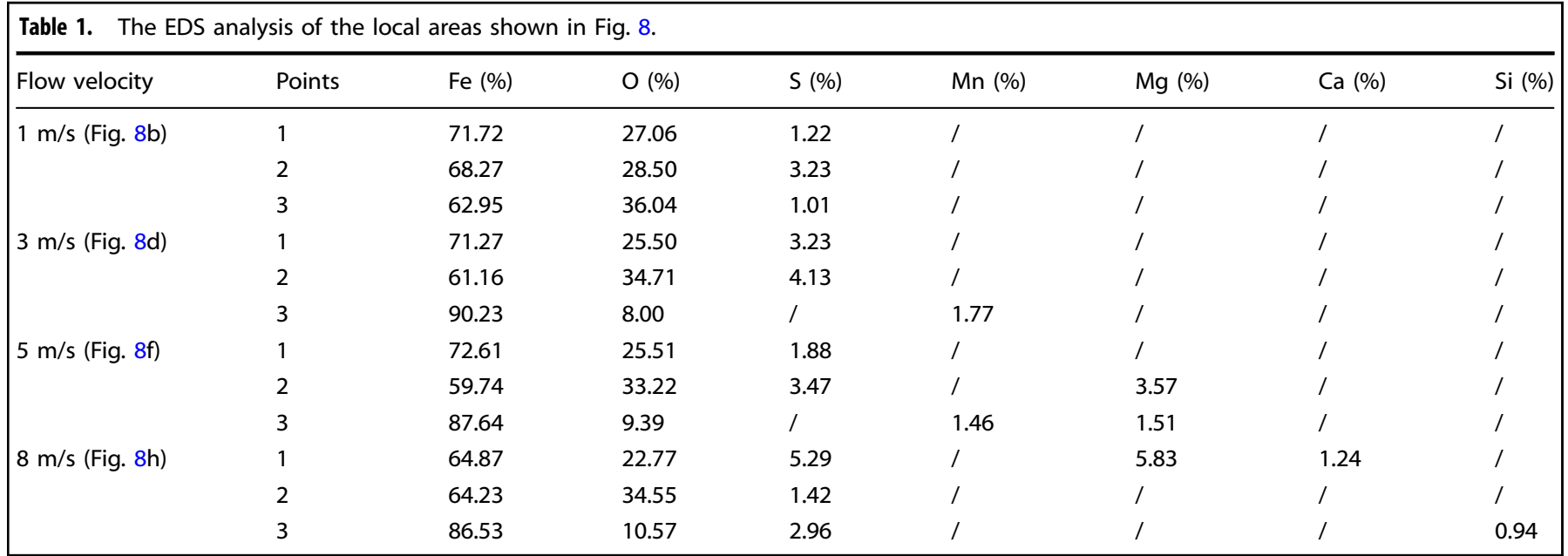

This work aims to figure out the FAC and erosion-corrosion performances of the marine carbon steel in natural seawater at different flow conditions. Firstly, the FAC performance of the EH 32 carbon steel in pure natural seawater (free of sand particles) of different flow velocities was studied using a submerged impingement jet system. Thereafter, the morphology and the composition of the rust layers formed at different flow velocities were characterized. Secondly, the pure erosion and the erosion -corrosion behaviours of the steel in the sand containing natural seawater at different flow velocities were investigated. In comparison to the experimental results of the FAC, pure erosion and erosion-corrosion at different flow velocities, both the general and localized interaction between erosion and corrosion in natural seawater are discussed.

\section{RESULTS}

\section{FAC tests}

The dynamic changes of the instant corrosion rate at different flow velocities are plotted in Fig. 1a. More details of the LPR measurements and fitting results are presented in Supplementary Fig. 1 and Table 1. At flow velocity of $1 \mathrm{~m} \mathrm{~s}^{-1}$, the corrosion rate of the EH 32 steel decreases significantly from 1.75 to $0.62 \mathrm{~mm} \mathrm{y}^{-1}$ after $12 \mathrm{~h}$ of test. Although the initial corrosion rate of the steel at $3 \mathrm{~m} \mathrm{~s}^{-1}$ is only $0.53 \mathrm{~mm} \mathrm{y}^{-1}$, which is dramatically lower than that at $1 \mathrm{~m} \mathrm{~s}^{-1}$, the corrosion rate keeps increasing and finally stabilises at $1.23 \mathrm{~mm} \mathrm{y}^{-1}$. The variation trends of corrosion rates at 5 and 8 $\mathrm{m} \mathrm{s}^{-1}$ are similar to that at $3 \mathrm{~m} \mathrm{~s}^{-1}$. The corrosion rates keep increasing from 0.55 to $1.72 \mathrm{~mm} \mathrm{y}^{-1}$, which are slightly higher than that of $3 \mathrm{~m} \mathrm{~s}^{-1}$. The general pure corrosion rates $\left(\dot{W}_{\mathrm{c} 0}\right)$ of the steel at different flow velocities are calculated and plotted in Fig. $1 \mathrm{~b}$. It is seen that the $\dot{W}_{\mathrm{c} 0}$ shifts positively from 0.89 to $1.27 \mathrm{~mm}$ $\mathrm{y}^{-1}$ with increasing the flow velocity from 1 to $5 \mathrm{~m} \mathrm{~s}^{-1}$. The corrosion rate of the steel at $8 \mathrm{~m} \mathrm{~s}^{-1}$ is similar to that at $5 \mathrm{~m} \mathrm{~s}^{-1}$. The results suggest that the increase of the flow velocity from 1 to $5 \mathrm{~m} \mathrm{~s}^{-1}$ slightly accelerates the FAC. However, further increase of the flow velocity from 5 to $8 \mathrm{~m} \mathrm{~s}^{-1}$ shows the negligible influence on the general FAC behaviour in natural seawater.

The surface morphologies of steel samples after FAC tests are presented in Fig. 2. A typical corrosion morphology of 'flow marks $^{9,25}$ (Fig. 2a) is observed at $1 \mathrm{~m} \mathrm{~s}^{-1}$ with a tip at the central part of the coupon and an expanded area at the downstream along the flow direction. The 'flow marks' are covered by brown rusts. It is seen from Fig. $2 c$ that the colour of the rust layer becomes darker at $3 \mathrm{~m} \mathrm{~s}^{-1}$. The distribution of the rust layer becomes more scattered which presents as 'comet tails' ${ }^{14}$ with small and narrow tails at the downstream. The corrosion morphologies of the steel at 5 and $8 \mathrm{~m} \mathrm{~s}^{-1}$ (Fig. 2e, g) are similar to that of $3 \mathrm{~m} \mathrm{~s}^{-1}$. The chemical compositions of the corrosion products generated at different flow velocities were characterized by Raman spectroscopy (Fig. 3a, c, e, and g). The results correspond to the local Points 1 and 2 which are marked in Fig. 2a, c, e, and g. It is seen that the corrosion products generated at all flow velocities are composed by lepidocrocite $(\gamma-\mathrm{FeOOH})$ and magnetite $\left(\mathrm{Fe}_{3} \mathrm{O}_{4}\right)$. The presence of corrosion products on the steel surface suggests that the fluid shear stress could not mechanically remove the rust layer. It further verifies that the mass loss induced by erosion could be ignored in pure natural seawater. 

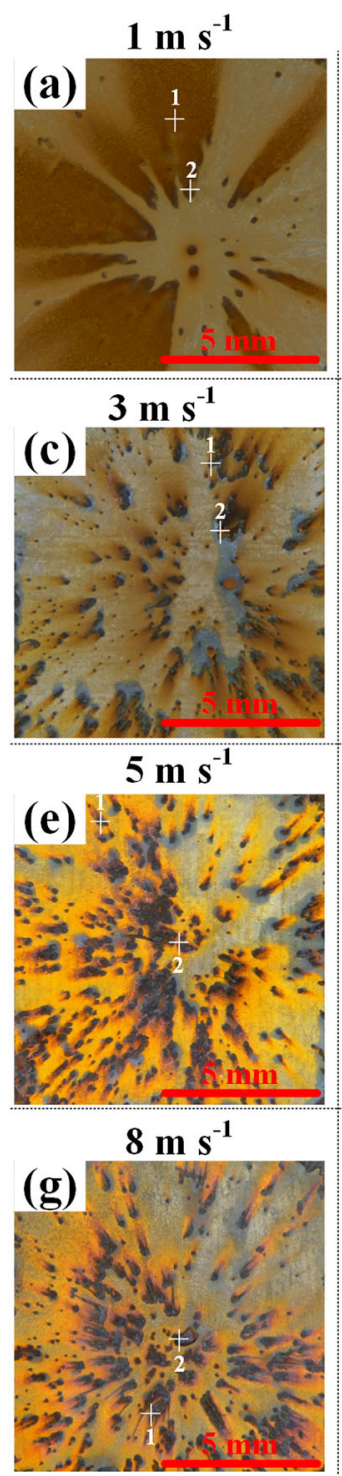
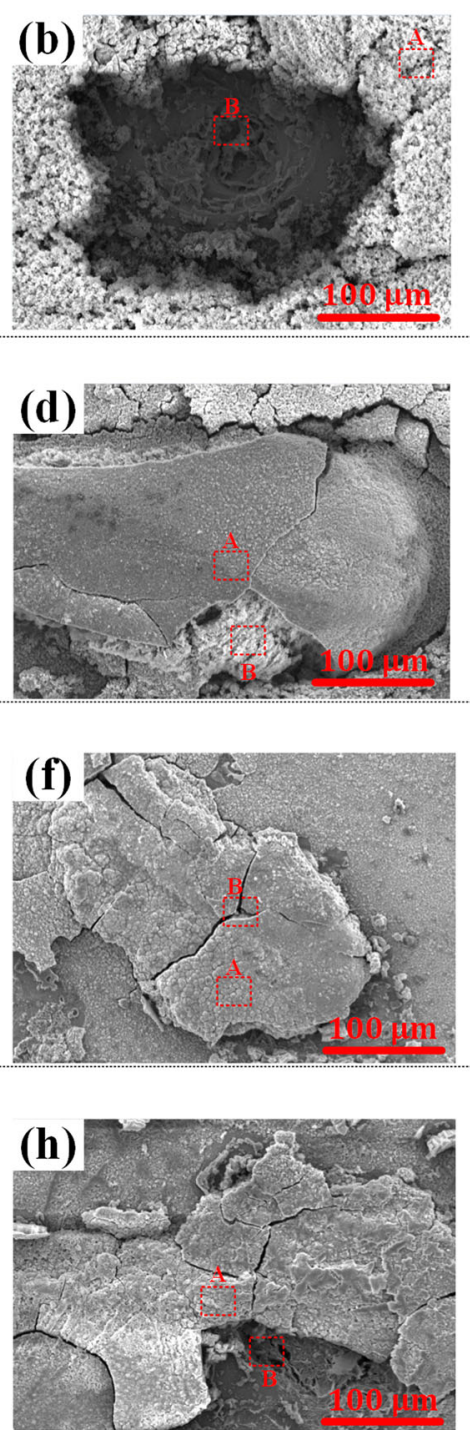

Local area $\mathrm{A}$

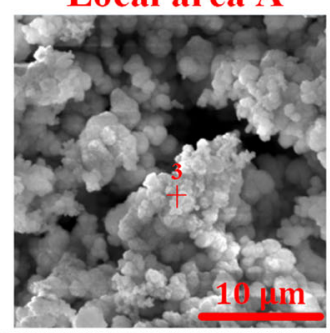

Local area $\mathrm{A}$

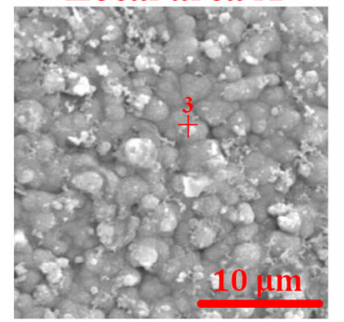

Local area $\mathrm{A}$

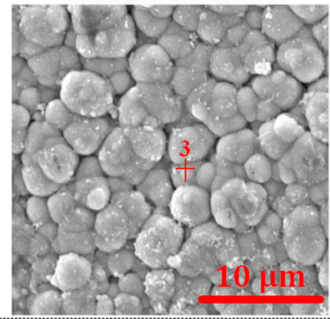

Local area $\mathrm{A}$

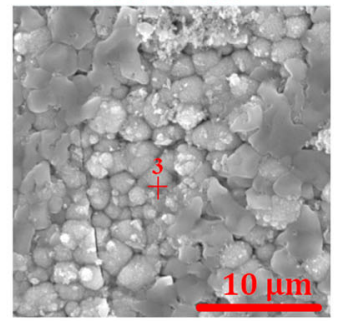

Local area B

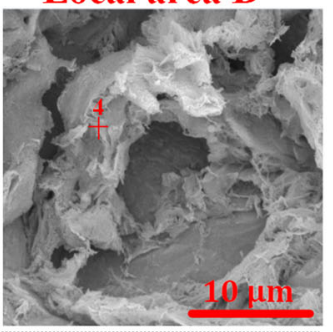

Local area $B$

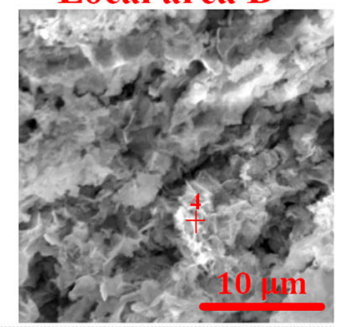

Local area B

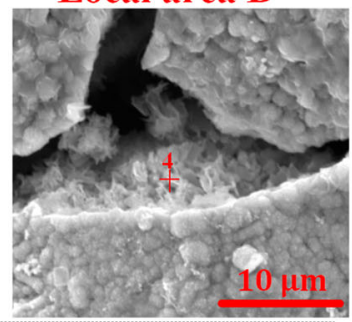

Local area B

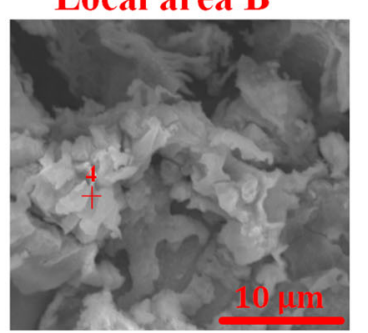

Fig. 2 Surface morphologies of the steel samples after tested in pure natural seawater. Photos (a, $\mathbf{c}, \mathbf{e}, \mathbf{g})$ and SEM images $(\mathbf{b}, \mathbf{d}, \mathbf{f}, \mathbf{h})$ of the samples after FAC tests at different flow velocities. $\mathbf{a}, \mathbf{b} 1 \mathrm{~m} \mathrm{~s}^{-1}, \mathbf{c}, \mathbf{d ~} 3 \mathrm{~m} \mathrm{~s}^{-1}, \mathbf{e}, \mathbf{f} 5 \mathrm{~m} \mathrm{~s}^{-1}, \mathbf{g}, \mathbf{h ~} 8 \mathrm{~m} \mathrm{~s}^{-1}$.

Consequently, the measured general FAC rate can be effectively considered as the pure corrosion rate.

More details of the surface morphologies and chemical compositions of the rust layers could be investigated from the scanning electron microscopy (SEM) images (Fig. 2b, d, f, and h) and the energy dispersive spectrometry (EDS) analysis (Fig. $3 \mathrm{~b}$, $d, f$, and $h$ ). Since the outer rust layer generated at $1 \mathrm{~m} \mathrm{~s}^{-1}$ is loose and porous, part of the outer rust layer falls off the steel surface (Fig. 2b). It is observed from local area A (Fig. 2b) that the outer rust layer presents as clusters of round particles with holes distributing in the layer. The inner rust layer which could be well observed from the local area B (Fig. 2b) presents as a grass-like morphology. EDS analysis (Fig. $3 \mathrm{~b}$ ) shows that the atomic ratios (by weight) of $\mathrm{Fe}$ and $\mathrm{O}$ in outer and inner rust layers (Point 3 and Point 4 in Fig. 2b) are 2.9 and 1.9, respectively. It suggests that the main compositions of the outer and inner layers formed at $1 \mathrm{~m} \mathrm{~s}^{-1}$ are $\mathrm{Fe}_{3} \mathrm{O}_{4}$ and $\gamma$ $\mathrm{FeOOH}$, respectively. As shown in Fig. $2 \mathrm{~d}$, the outer rust layer presents as compactly connected small particles at $3 \mathrm{~m} \mathrm{~s}^{-1}$. Likewise, the round particles become more significant and compact at both $5 \mathrm{~m} \mathrm{~s}^{-1}$ (Fig. 2f) and $8 \mathrm{~m} \mathrm{~s}^{-1}$ (Fig. 2h). It is also seen from the EDS results of Points 3 (Fig. $3 d, f$, and $h$ ) that the atomic ratios of $\mathrm{Fe}$ and $\mathrm{O}$ are around 2.6-2.9, suggesting that the main composition of the outer rust layer is $\mathrm{Fe}_{3} \mathrm{O}_{4}$ at $3-8 \mathrm{~m}$ $\mathrm{s}^{-1}$. Although the outer rust layer becomes relatively compact at higher flow velocities, some cracks and local peeling are still observed on the outer rust layer. The porous and grass-like inner rust layers could be seen from the local peeling areas and cracks. According to the EDS results of Points 4 (Fig. $3 d, f$, and h), it is deduced that the main composition of the inner rust layer is $\mathrm{\gamma}-\mathrm{FeOOH}$ as the atomic ratios of $\mathrm{Fe}$ and $\mathrm{O}$ are around 1.6-1.7.

The corroded morphologies of the steel samples after removing the rust layers are presented in Fig. 4. As shown in Fig. 4a, some small pits are formed at the central part of the coupon. The FAC would initiate from these small pits and finally propagate to 'flow marks'. The corrosion pattern would transfer from 'flow marks' to pits (Fig. 4b) with increasing the flow velocity from 1 to $3 \mathrm{~m} \mathrm{~s}^{-1}$. It is seen from Fig. $4 c, d$ that the density of the pits shows an obvious increase when the flow velocity further increases to 5 and $8 \mathrm{~m} \mathrm{~s}^{-1}$. The measured pit depths are in the range of $50-70 \mu \mathrm{m}$ at velocities of $3-8 \mathrm{~m} \mathrm{~s}^{-1}$. Only a few deep pits with maximum depth of $100 \mu \mathrm{m}$ are observed at $8 \mathrm{~m} \mathrm{~s}^{-1}$. 


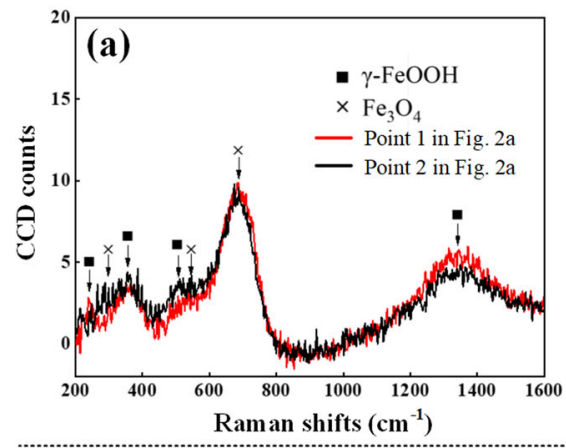

(b) EDS of Point 3 in Fig. $2 b$

EDS of Point 4 in Fig. 2b
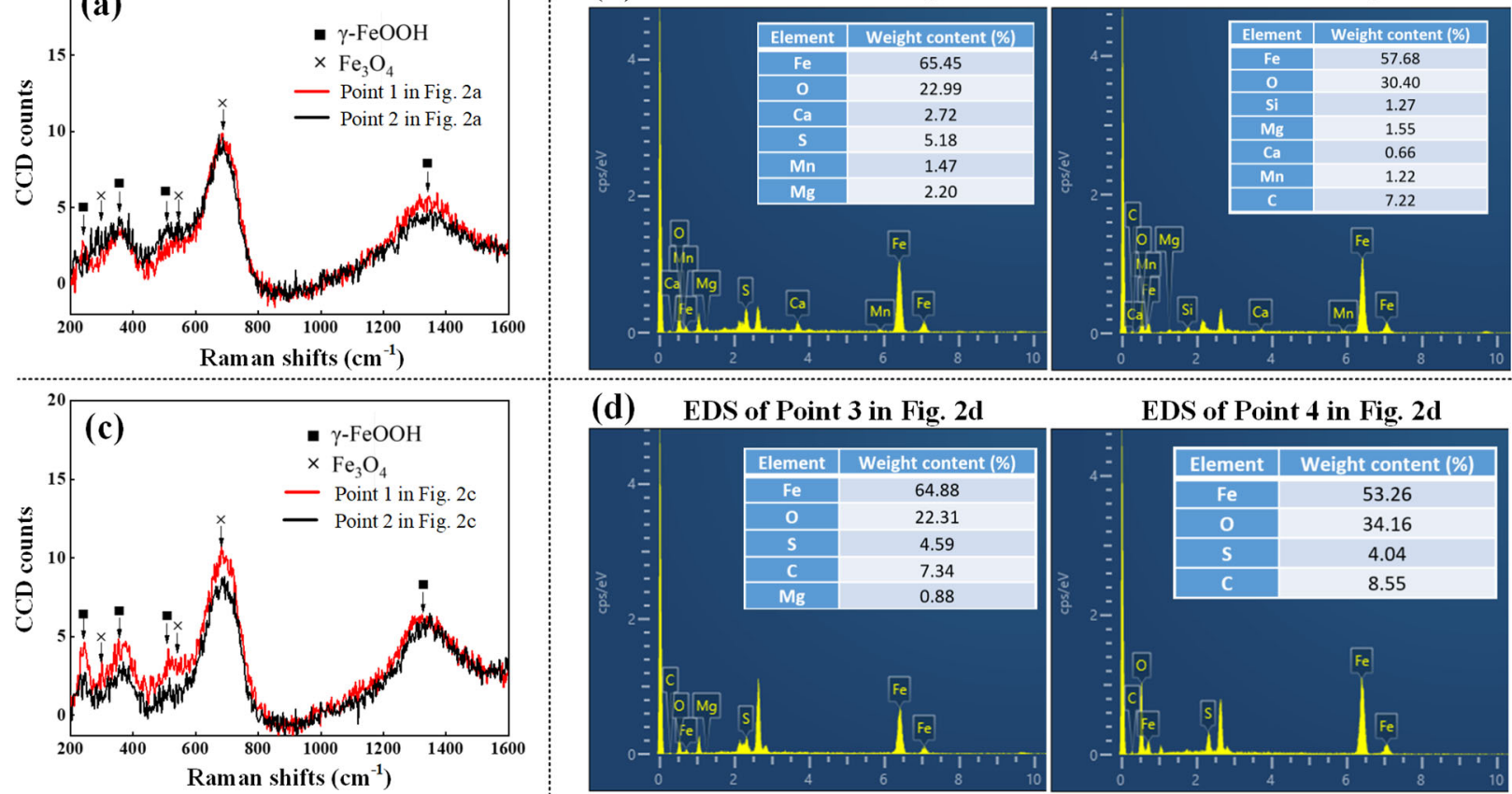

(d) EDS of Point 3 in Fig. 2d

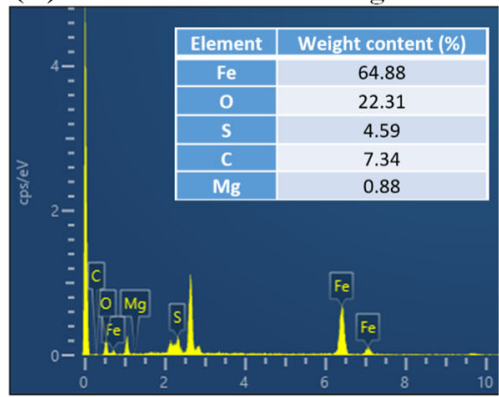

EDS of Point 4 in Fig. 2d

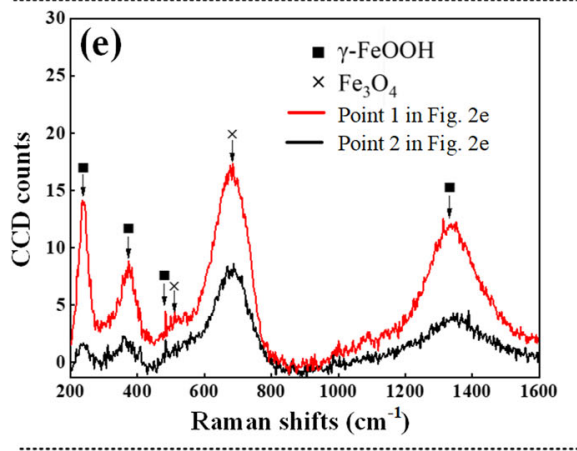

(f)
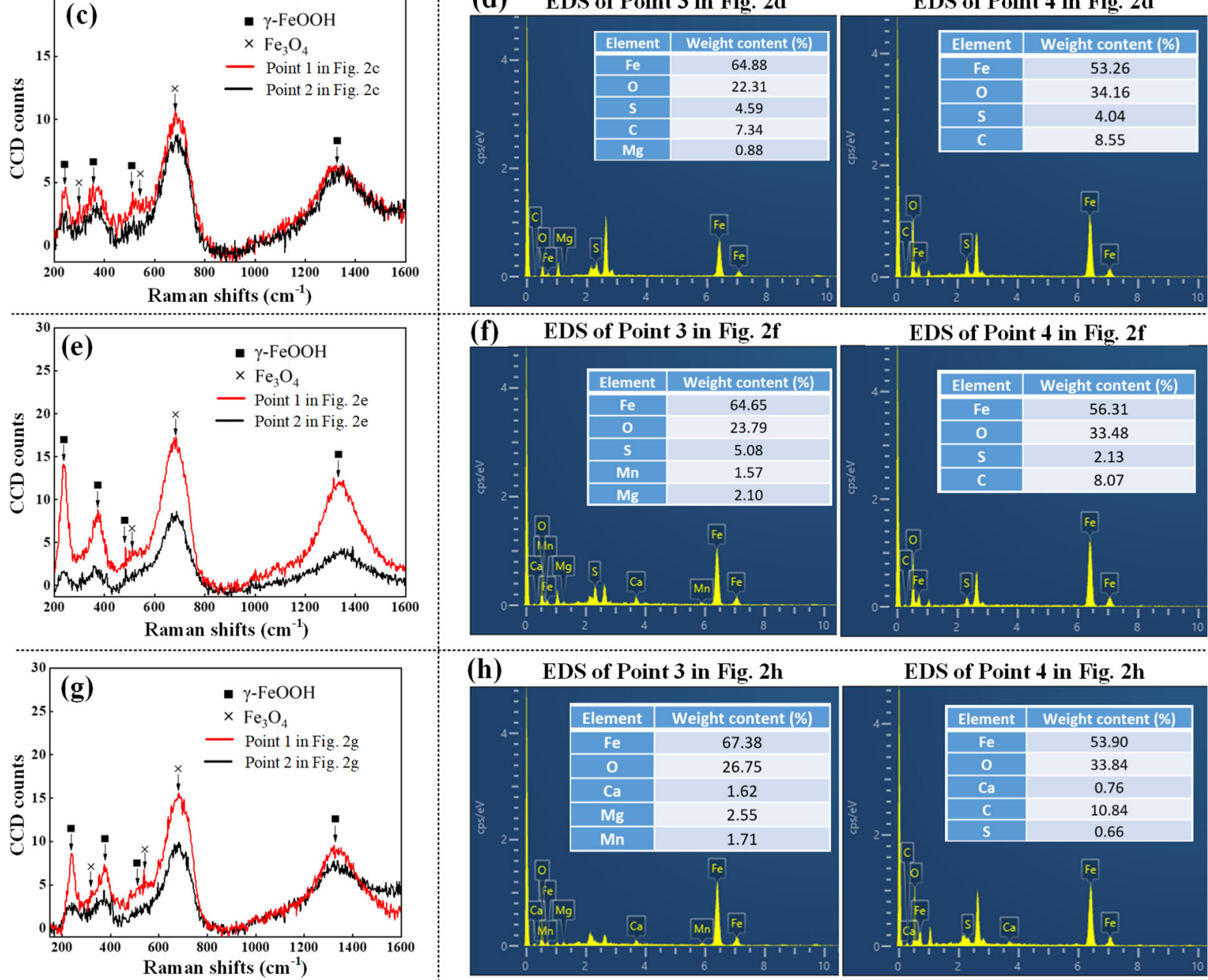

\section{(h) EDS of Point 3 in Fig. $2 h$}

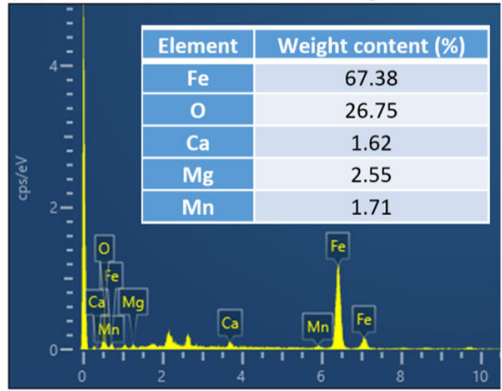

EDS of Point 4 in Fig. $2 f$

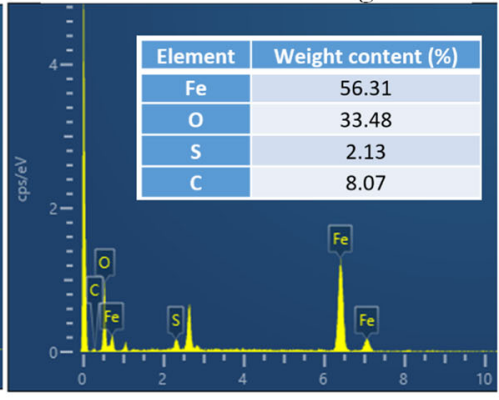

EDS of Point 4 in Fig. $2 h$

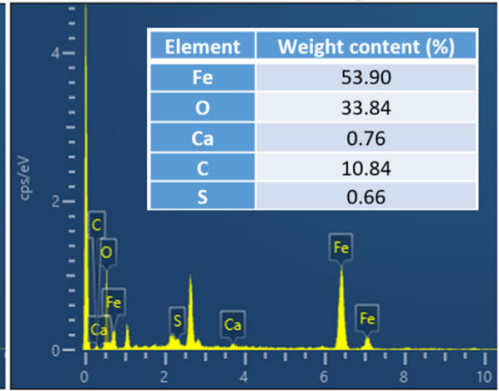

Fig. 3 Characterization of the corrosion products generated in pure natural seawater. The Raman spectroscopy (a, c, e, g) and EDS results $(\mathbf{b}, \mathbf{d}, \mathbf{f}, \mathbf{h})$ of the local points presented in Fig. 2 at different flow velocities. a, b $1 \mathrm{~m} \mathrm{~s}^{-1}, \mathbf{c}, \mathbf{d ~} 3 \mathrm{~m} \mathrm{~s}^{-1}, \mathbf{e}, \mathbf{f} 5 \mathrm{~m} \mathrm{~s}^{-1}, \mathbf{g}, \mathbf{h ~} 8 \mathrm{~m} \mathrm{~s} \mathrm{~s}^{-1}$.

\section{Pure erosion tests}

Since the corrosion components were eliminated by applying an external cathodic potential, the pure erosion rate in the sandentraining seawater at different flow velocities could be obtained from gravimetric measurements. The general pure erosion rates $\left(\dot{W}_{\mathrm{e} 0}\right)$ of the three repeated tests are calculated and plotted in Fig. 5. More details of the gravimetric measurement results are presented in Supplementary Table 2. The pure erosion rates are measured to be small when the velocity of the slurry is lower than $5 \mathrm{~m} \mathrm{~s}^{-1}$. The pure erosion rate significantly increases from 0.60 to $7.21 \mathrm{~mm} \mathrm{y}^{-1}$ with increasing the flow velocity from 5 to $8 \mathrm{~m} \mathrm{~s}^{-1}$. According to the pure erosion model proposed in literature ${ }^{39,40}$, the $\dot{W}_{\mathrm{e} 0}$ induced by the normal sand impacts can be expressed as:

$$
\dot{W}_{\mathrm{e} 0}=K v^{a}
$$

where $\dot{W}_{\mathrm{e} 0}$ is the pure erosion rate, $K$ is a constant specific to the material, $v$ is the impact velocity of the sand particles, $a$ is a material-specific velocity exponent, which normally ranges between 2 and 3 for metals. The fitted result of the measured $\dot{W}_{\text {eo }}$ using Eq. 1 ( $a$ is adopted as 3 according to the ref. ${ }^{40}$ ) is also plotted in Fig. 5. The dramatic increase of $\dot{W}_{\mathrm{e} 0}$ with increasing the flow velocity from 5 to $8 \mathrm{~m} \mathrm{~s}^{-1}$ is induced by the exponential rise of the erosion steel loss with respect to the flow velocity. 
(a) $1 \mathrm{~m} \mathrm{~s}^{-1}$

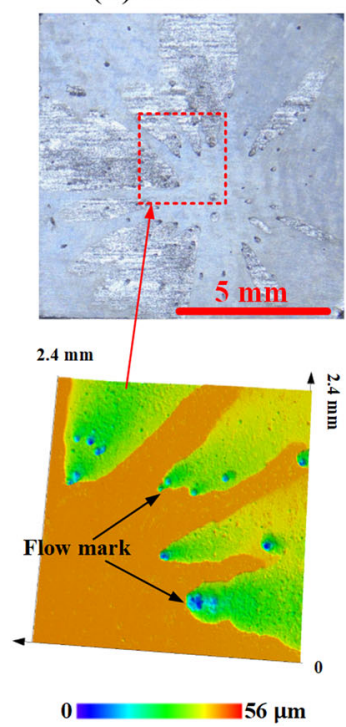

(b) $3 \mathrm{~m} \mathrm{~s}^{-1}$

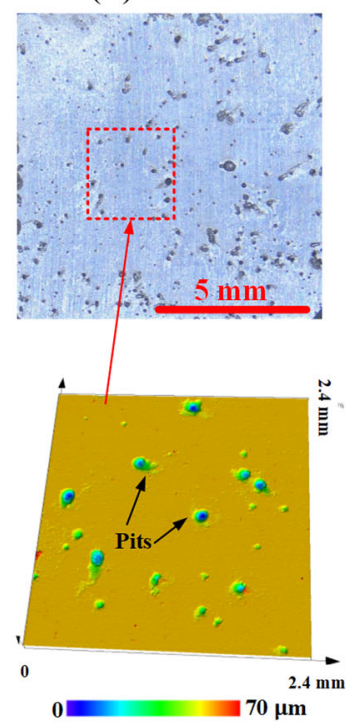

(c) $5 \mathrm{~m} \mathrm{~s}^{-1}$

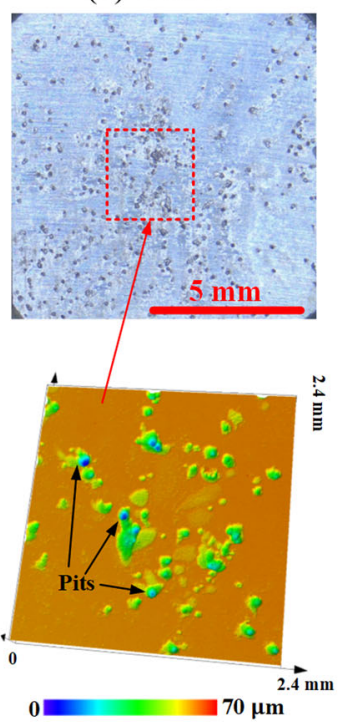

(d) $8 \mathrm{~m} \mathrm{~s}^{-1}$

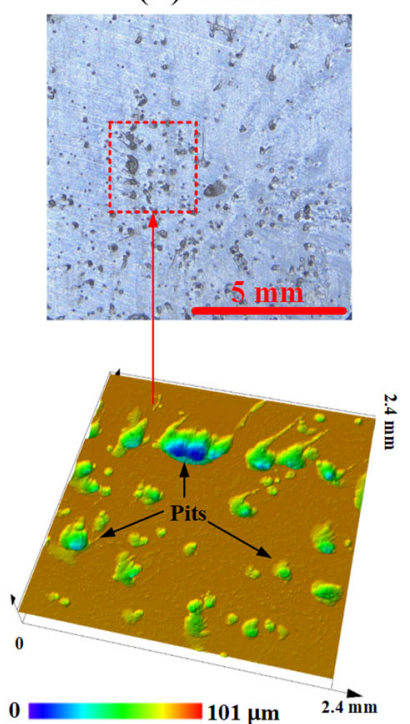

Fig. 4 Photos and local 3D profiles of the steel tested in pure natural seawater with rust layers removed. a $1 \mathrm{~m} \mathrm{~s}^{-1}, \mathbf{b ~} 3 \mathrm{~m} \mathrm{~s}^{-1}, \mathbf{c} 5 \mathrm{~m} \mathrm{~s}^{-1}$, and $\mathbf{d} 8 \mathrm{~m} \mathrm{~s}^{-1}$.

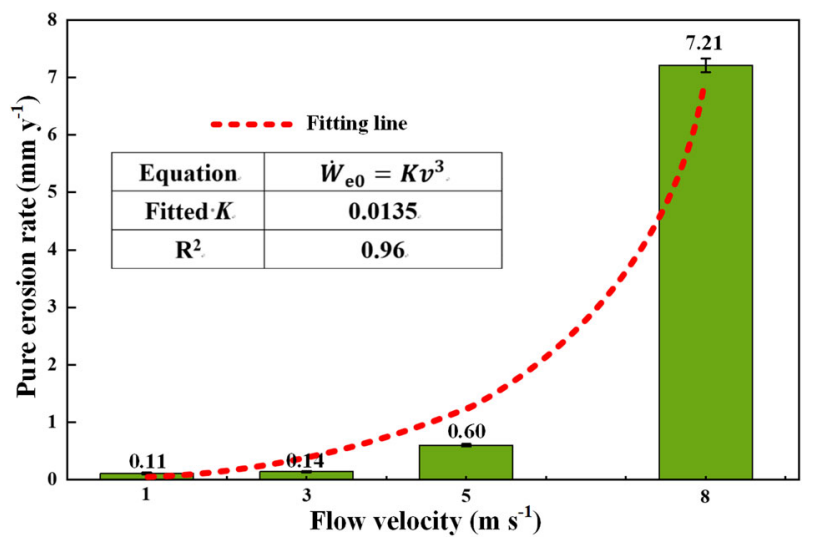

Fig. 5 The general pure erosion rate of EH 32 steel at different flow velocities. The general pure rate is fitted from the pure erosion equation and the fitting results are presented as the dashed line in the figure. The error bars represent standard deviations of the three repeated tests at each flow velocity.

The surface morphologies of the EH 32 steel after being tested at different flow velocities are shown in Fig. 6. It is seen from Fig. $6 a$ that the sand impacts could only slightly deform the steel surface and cause some minor micro-cutting at $1 \mathrm{~m} \mathrm{~s}^{-1}$. The cutting grooves and the impingement craters become deeper and more obvious at $3 \mathrm{~m} \mathrm{~s}^{-1}$ (Fig. 6b). The whole surface of the steel becomes rough, and the density of the craters increases obviously at $5 \mathrm{~m} \mathrm{~s}^{-1}$ (Fig. 6c). As shown in Fig. 6d, the damage of the steel becomes more serious and some local work-hardened areas are found at $8 \mathrm{~m} \mathrm{~s}^{-1}$. It is seen from Fig. $6 a-d$ that the surface roughness $(\mathrm{Ra})$ of the steel increases from 0.108 to $0.425 \mu \mathrm{m}$ with increasing the flow velocity from 1 to $8 \mathrm{~m} \mathrm{~s}^{-1}$.

\section{Erosion-corrosion tests}

The results of the erosion-corrosion tests in sand-entraining seawater are plotted in Fig. 7. More details of the LPR and gravimetric measurement results are presented in Supplementary Fig. 2 and Tables 3, 4. It is seen from Fig. 7a that the corrosion rate of the EH 32 steel decreases sharply from 2.47 to $0.60 \mathrm{~mm} \mathrm{y}^{-1}$ at 1 $\mathrm{m} \mathrm{s}^{-1}$. The variation trend is similar to the FAC performance at $1 \mathrm{~m}$ $\mathrm{s}^{-1}$. The corrosion rates of all samples show significant increases in the $12 \mathrm{~h}$ of test at $3-8 \mathrm{~m} \mathrm{~s}^{-1}$. The corrosion rate shifts from 0.88 to $3.71 \mathrm{~mm} \mathrm{y}^{-1}$ at $3 \mathrm{~m} \mathrm{~s}^{-1}$. The initial corrosion rate is around 1.76 $\mathrm{mm} \mathrm{y}^{-1}$ at $5 \mathrm{~m} \mathrm{~s}^{-1}$. The corrosion rate finally increases to $5.20 \mathrm{~mm}$ $\mathrm{y}^{-1}$ after $12 \mathrm{~h}$ of test. The corrosion rate intensely increases from 2.46 to $7.31 \mathrm{~mm} \mathrm{y}^{-1}$ at $8 \mathrm{~m} \mathrm{~s}^{-1}$. It is seen from Fig. $7 \mathrm{~b}$ that the general corrosion rate $\left(\dot{W}_{\mathrm{c}}\right)$ shows a linear increase from 1.07 to $6.30 \mathrm{~mm} \mathrm{y}^{-1}$ with increasing the flow velocity. The total steel loss rate $\left(\dot{W}_{\mathrm{t}}\right)$ presents a linear increasing trend from 1.78 to $8.10 \mathrm{~mm}$ $\mathrm{y}^{-1}$ with increasing the flow velocity from 1 to $5 \mathrm{~m} \mathrm{~s}^{-1}$. The $\dot{W}_{\mathrm{t}}$ has a dramatic increase from 8.10 to $17.21 \mathrm{~mm} \mathrm{y}^{-1}$ when the flow velocity further increases from 5 to $8 \mathrm{~m} \mathrm{~s}^{-1}$. The general erosion rates $\left(\dot{W}_{\mathrm{e}}\right)$ at different flow velocities are calculated from the differences between the $\dot{W}_{\mathrm{t}}$ and $\dot{W}_{\mathrm{c}}$. It is seen that the variation trend of the $\dot{W}_{\mathrm{e}}$ is similar to that of $\dot{W}_{\mathrm{t}}$ which presents an intense increase from 5 to $8 \mathrm{~m} \mathrm{~s}^{-1}$. The $\dot{W}_{\mathrm{e}}$ is close to the $\dot{W}_{\mathrm{c}}$ at $1-5 \mathrm{~m} \mathrm{~s}^{-1}$. However, the $\dot{W}_{\mathrm{e}}$ climbs to $10.91 \mathrm{~mm} \mathrm{y}^{-1}$ at $8 \mathrm{~m} \mathrm{~s}^{-1}$, which is dramatically higher than the $\dot{W}_{\mathrm{c}}$.

The synergistic components of erosion enhanced corrosion $\left(\dot{W}_{c}^{\mathrm{e}}\right)$ and corrosion enhanced erosion $\left(\dot{W}_{\mathrm{e}}^{\mathrm{c}}\right)$ are further calculated and plotted in Fig. 7c, d, respectively. It is seen from Fig. 7c that the $\dot{W}_{c}^{\text {e }}$ is tiny $\left(0.17 \mathrm{~mm} \mathrm{y}^{-1}\right)$ at $1 \mathrm{~m} \mathrm{~s}^{-1}$. The $\dot{W}_{c}^{\mathrm{e}}$ shows an intense increase to $1.60 \mathrm{~mm} \mathrm{y}^{-1}$ at $3 \mathrm{~m} \mathrm{~s}^{-1}$. The $\dot{W}_{c}^{\mathrm{e}}$ becomes higher than the $\dot{W}_{\mathrm{c} 0}$, which counts over $60 \%$ of the $W_{c}$ in this case. The $\dot{W}_{c}^{\text {e }}$ keeps increasing with further increasing the flow velocity from 3 to $8 \mathrm{~m}$ $\mathrm{s}^{-1}$. The contribution of $\dot{W}_{c}^{\mathrm{e}}$ reaches $83 \%$ of the $\dot{W}_{\mathrm{c}}$ at $8 \mathrm{~m} \mathrm{~s}^{-1}$, indicating that the erosion enhanced corrosion is the dominated factor of corrosion in the natural seawater of $3-8 \mathrm{~m} \mathrm{~s}^{-1}$. It is seen from Fig. $7 \mathrm{~d}$ that the $\dot{W}_{\mathrm{e}}^{\mathrm{c}}$ are $0.60,2.33 \mathrm{~mm} \mathrm{y}^{-1}$, and $3.26 \mathrm{~mm} \mathrm{y}^{-1}$ at the flow velocities of 1,3 , and $5 \mathrm{~m} \mathrm{~s}^{-1}$, respectively, which counts 85,94 , and $84 \%$ of the $\dot{W}_{\text {e }}$ at each flow velocity. It indicates that almost all of the erosion component is induced by the corrosion enhanced erosion at $1-5 \mathrm{~m} \mathrm{~s}^{-1}$. The $\dot{W}_{\mathrm{e}}^{\mathrm{c}}$ only shows a slight increase to $3.69 \mathrm{~mm} \mathrm{y}^{-1}$ at $8 \mathrm{~m} \mathrm{~s}^{-1}$, which only counts $34 \%$ of the $\dot{W}_{\mathrm{e}}$. It indicates that pure erosion becomes the main contributor to the erosion component at $8 \mathrm{~m} \mathrm{~s}^{-1}$.

The surface morphologies of the steel samples after $12 \mathrm{~h}$ of erosion-corrosion tests are presented in Fig. 8. As shown in Fig. $8 a$, the 'flow mark' morphology is similar to the FAC performance at $1 \mathrm{~m} \mathrm{~s}^{-1}$. The 'flow marks' are covered by porous brown rusts as 
(a) $1 \mathrm{~m} \mathrm{~s}^{-1}$

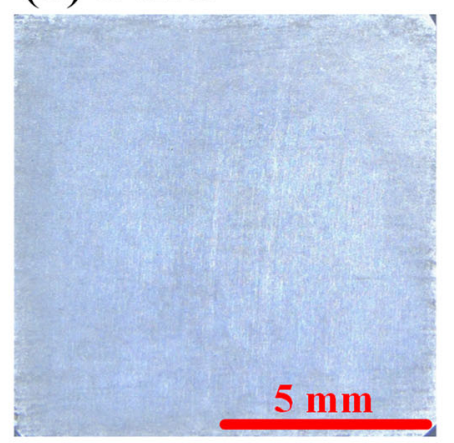

(b) $3 \mathrm{~m} \mathrm{~s}^{-1}$

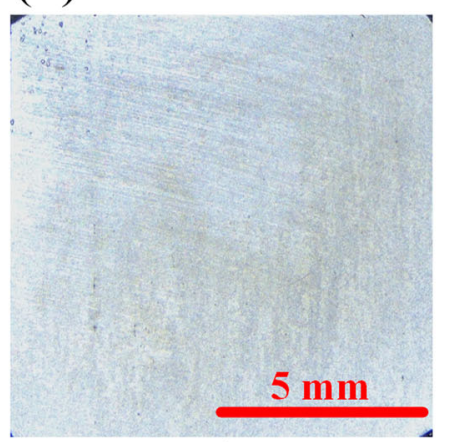

(c) $5 \mathrm{~m} \mathrm{~s}^{-1}$

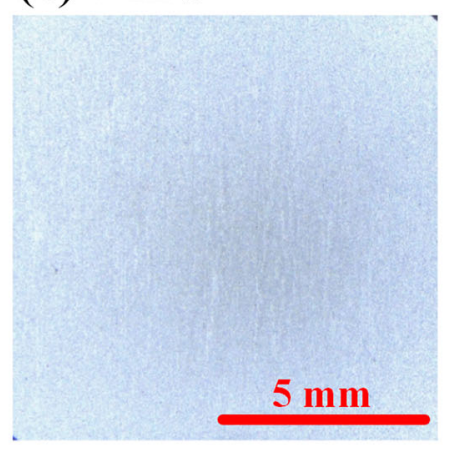

(d) $8 \mathrm{~m} \mathrm{~s}^{-1}$

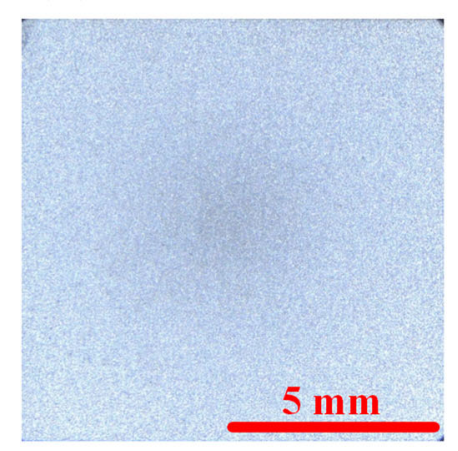

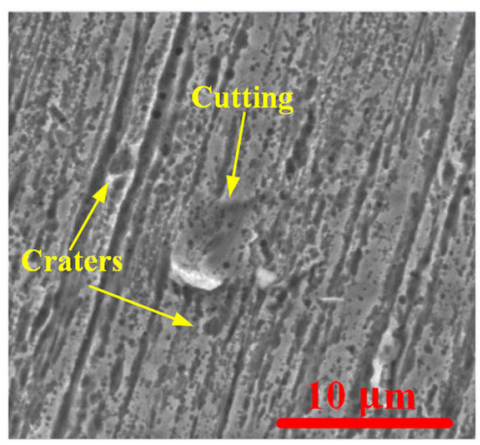
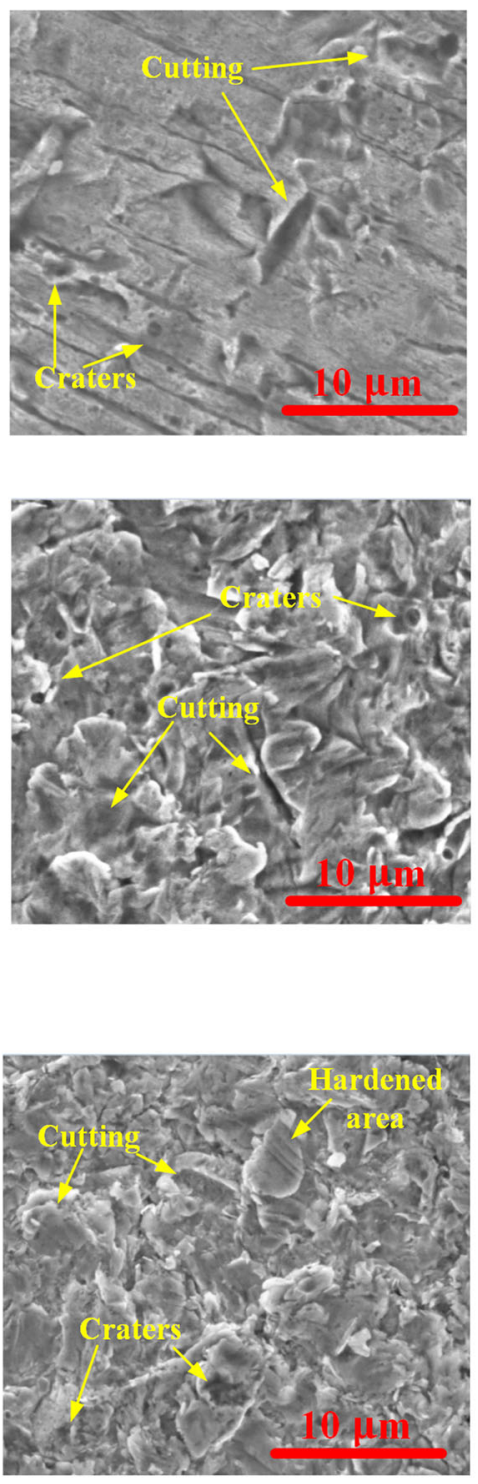
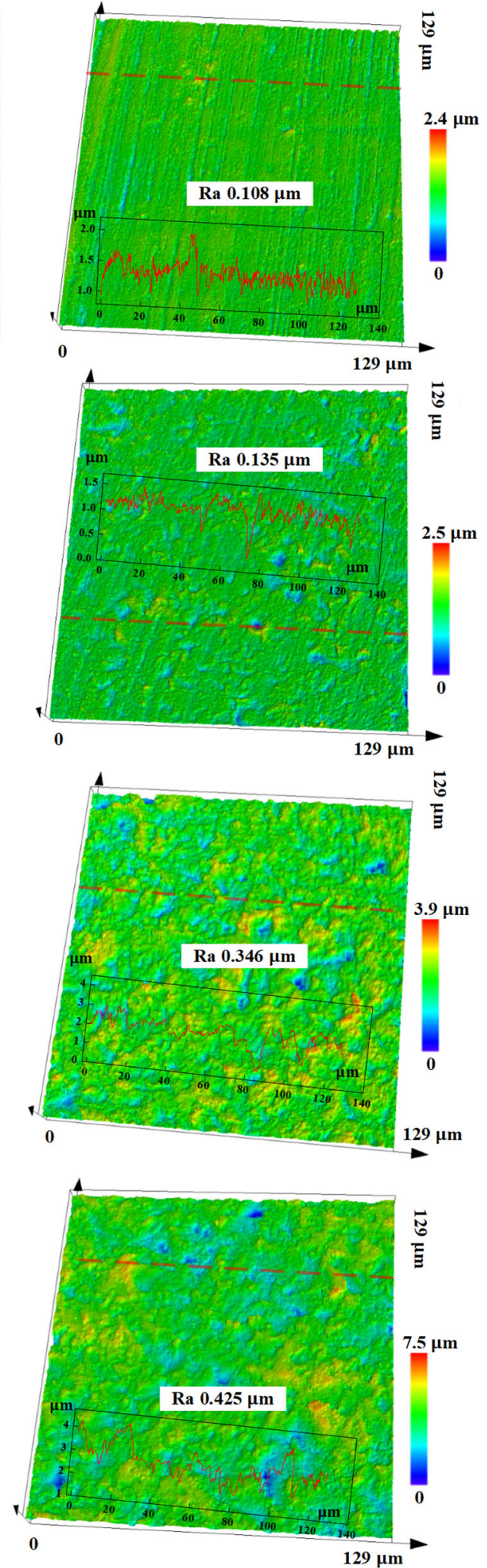

Fig. 6 Photos, local SEM images, and local 3D profiles of the steel samples after pure erosion experiments at different flow velocities. a $1 \mathrm{~m} \mathrm{~s}^{-1}, \mathbf{b} 3 \mathrm{~m} \mathrm{~s}^{-1}, \mathbf{c} 5 \mathrm{~m} \mathrm{~s}^{-1}$, and d $8 \mathrm{~m} \mathrm{~s}^{-1}$.

well. It is seen from Fig. $8 \mathrm{c}$ that the areas of the 'flow marks' become small and some scattered pits appear on the steel surface at $3 \mathrm{~m} \mathrm{~s}^{-1}$. In this case, most of the corrosion products are concentrated in the 'flow marks' and pits. The erosion-corrosion morphologies present as completely pitting damage when the flow velocity further increases to $5 \mathrm{~m} \mathrm{~s}^{-1}$ (Fig. 8e) and $8 \mathrm{~m} \mathrm{~s}^{-1}$ (Fig. 8g). The corrosion products are observed inside the pits. The results of the Raman spectroscopy in the sand-entraining seawater 

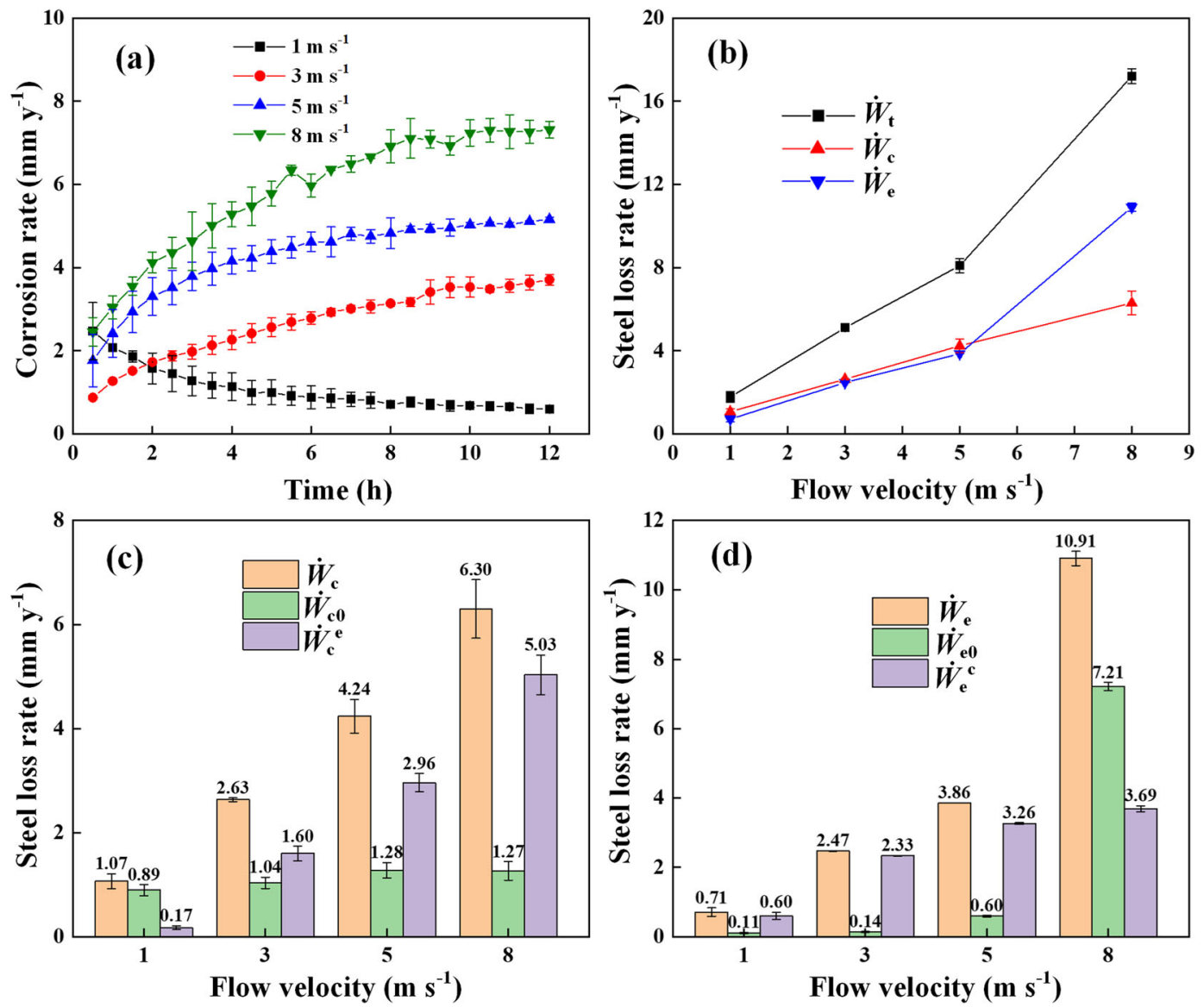

Fig. 7 The measurement and the calculation results of the erosion-corrosion at different flow velocities. a Time dependence of the instant corrosion rates. b The total steel loss rate, general corrosion rate, and erosion rate. c The general corrosion rate, pure corrosion rate, and erosion enhanced corrosion rate. $\mathbf{d}$ The general erosion rate, pure erosion rate, and corrosion enhanced erosion rate. The error bars represent standard deviations of the three repeated tests at each flow velocity.

at different flow velocities are quite similar to those presented in Fig. 3. The corrosion products are composed of $\mathrm{y}-\mathrm{FeOOH}$ and $\mathrm{Fe}_{3} \mathrm{O}_{4}$ for all the erosion-corrosion conditions. Accordingly, the Raman spectroscopy of the rust layers formed at erosion - corrosion conditions is not presented.

Similar to the FAC performance at $1 \mathrm{~m} \mathrm{~s}^{-1}$, the outer layer presents as clusters of round particles (local area A in Fig. 8b) and the inner layer presents as grass-like rusts (local area B in Fig. $8 \mathrm{~b}$ ) after erosion-corrosion at $1 \mathrm{~m} \mathrm{~s}^{-1}$. The chemical compositions acquired from EDS analysis of the local areas shown in Fig. 8 are listed in Table 1. More details of the EDS results are presented in Supplementary Fig. 3. It is found that the atomic ratio of the Fe and $O$ decreases from 2.65 (Point 1 in Fig. 8b) to 1.74 (Point 3 in Fig. 8b). It indicates that the main compositions of the outer rust layer and inner rust layer are $\mathrm{Fe}_{3} \mathrm{O}_{4}$ and $\gamma-\mathrm{FeOOH}$, respectively. With increasing the flow velocity to 3 and $5 \mathrm{~m} \mathrm{~s}^{-1}$, the boundaries of the damaged areas are clearly identified from the SEM images (Fig. 8d, f). Most of the corrosion products are located inside the 'flow mark' and pit. The outer rust layer which presents as closely connected particles is clearly seen from the local areas A in Fig. $8 \mathrm{~d}$, $\mathrm{f}$. The atomic ratios of the outer rust layers (Points 1 in Fig. $8 \mathrm{~d}, \mathrm{f}$ ) formed at 3 and $5 \mathrm{~m} \mathrm{~s}^{-1}$ are 2.80 and 2.85, respectively, indicating that the compact outer layer is almost composed of $\mathrm{Fe}_{3} \mathrm{O}_{4}$. Some grass-like rusts are observed at the edges of the compact outer layer at local areas B (Fig. 8d, f). The atomic ratios of the local Points 2 where are located in the grass-like rusts are 1.76 and 1.80, suggesting that the main composition of these rusts is $\gamma$-FeOOH. It is seen from the EDS results of Points 3 (Fig. $8 d$, f) that the contents of $\mathrm{O}$ are extremely low. It indicates that the substance located at the boundary of the 'flow mark' and the pit is the steel debris rather than the corrosion products. When the flow velocity further increases to $8 \mathrm{~m} \mathrm{~s}^{-1}$, it is seen from the local area $A$ in Fig. $8 \mathrm{~h}$ that the corrosion products inside the pit become porous, which present as clusters of round particles again. The atomic ratio of the corrosion products at Point 1 (Fig. $8 \mathrm{~h}$ ) is 2.85 , indicating that the main composition of the corrosion products is $\mathrm{Fe}_{3} \mathrm{O}_{4}$ inside the pit. A ring platform consisting of small debris is seen at the pits boundary. It is seen from the local area B (Fig. 8h) there is a small crevice between the debris and the pit boundary. The atomic ratio of the corrosion products formed at the vicinity of the ring platform (Point 2 in Fig. 8h) is 1.87, suggesting a main composition of $\mathrm{y}$ - $\mathrm{FeOOH}$. The EDS result shows that the atomic ratio of $\mathrm{Fe}$ and $\mathrm{O}$ at Point 3 (Fig. 8h) is 8.18 , indicating that the main content of the debris on the ring is pure steel as well.

The damage morphologies of the steel samples after erosion -corrosion experiments (with rust layer removed) are presented in Fig. 9. The 'flow mark' morphology (Fig. 9a) is similar to that observed in FAC test at $1 \mathrm{~m} \mathrm{~s}^{-1}$. It indicates that the effect of sand impingements on the steel degradation is not obvious in this case. When the flow velocity increases to $3 \mathrm{~m} \mathrm{~s}^{-1}$, the main morphology changes to a mixture of small 'flow marks' and pits with tails (Fig. 9b). The depths of the pits at the tip of the 'flow mark' reach $100 \mu \mathrm{m}$, which are much higher than the general pit depth (50 $-70 \mu \mathrm{m})$ shown in Fig. 4b. As shown in Fig. 9c, the pits become more round and the general pit depth increases to $95-110 \mu \mathrm{m}$ at $5 \mathrm{~m} \mathrm{~s}^{-1}$. The density of the pits shows a significant increase with the impact velocity further increasing to $8 \mathrm{~m} \mathrm{~s}^{-1}$ (Fig. 9d). However, the general pit depth of $8 \mathrm{~m} \mathrm{~s}^{-1}$ is similar to that of 

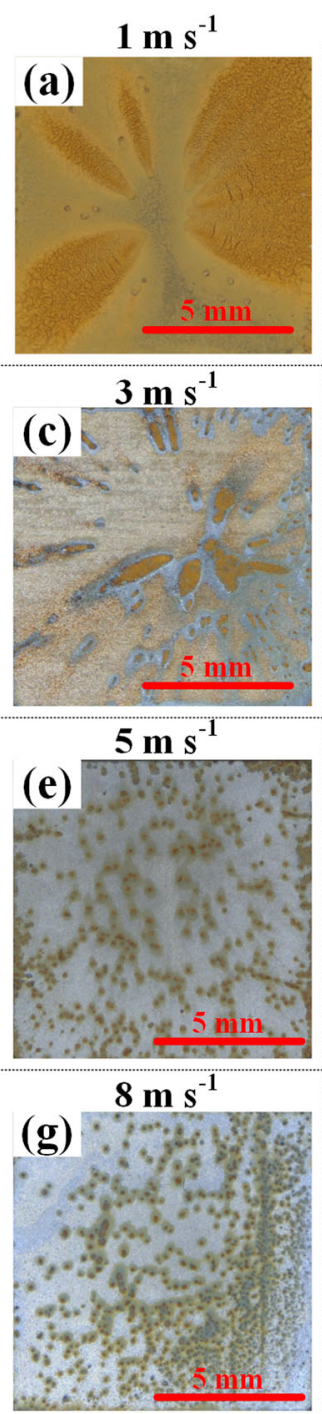
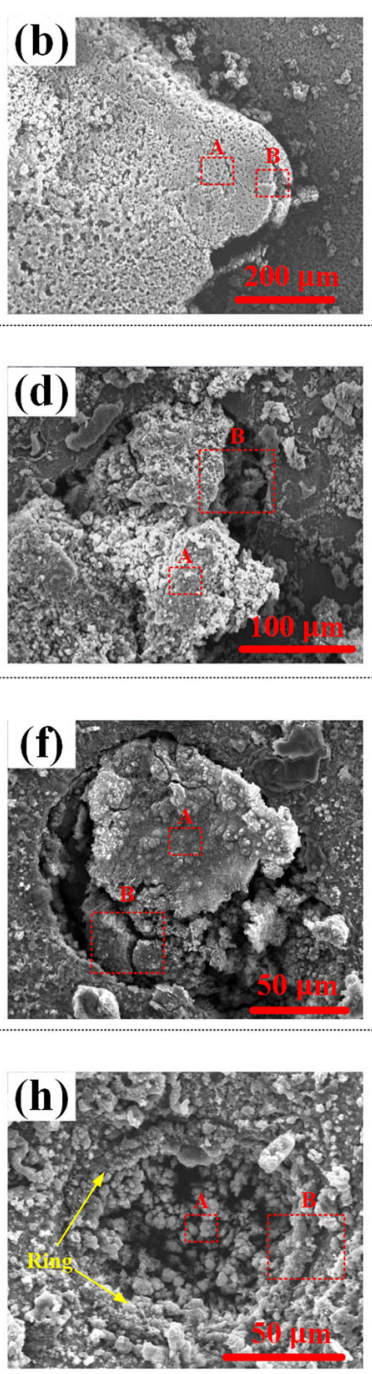

Local area $A$

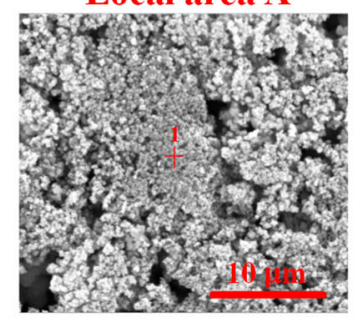

Local area $A$

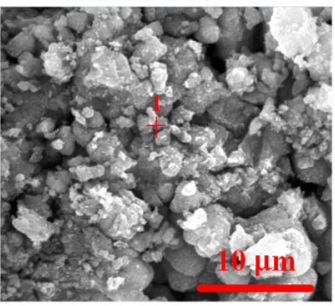

Local area $\mathbf{A}$

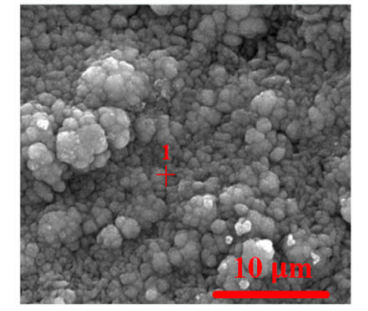

Local area $A$

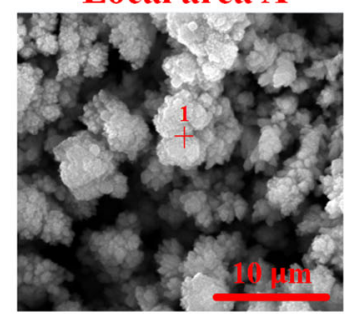

Local area $B$

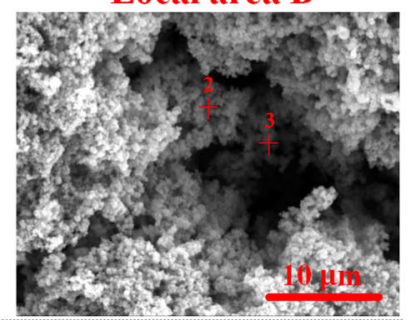

Local area B

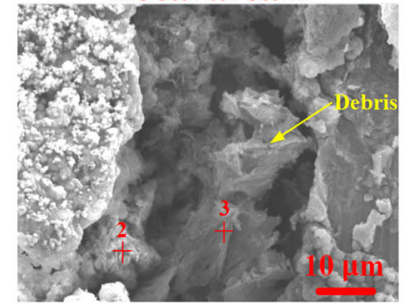

Local area B

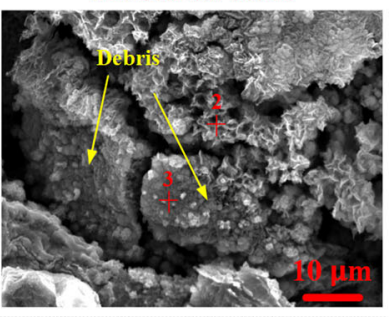

Local area B

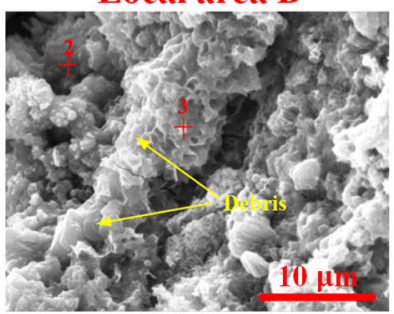

Fig. 8 Surface morphologies of the steel samples after tested in natural seawater containing sand particles. Photos (a, $\mathbf{c}, \mathbf{e}, \mathbf{g})$ and SEM images $(\mathbf{b}, \mathbf{d}, \mathbf{f}, \mathbf{h})$ of the samples after erosion-corrosion tests at different flow velocities. $\mathbf{a}, \mathbf{b} 1 \mathrm{~m} \mathrm{~s}^{-1}, \mathbf{c}, \mathbf{d ~} 3 \mathrm{~m} \mathrm{~s}^{-1}, \mathbf{e}, \mathbf{f} 5 \mathrm{~m} \mathrm{~s}^{-1}, \mathbf{g}, \mathbf{h ~} 8 \mathrm{~m} \mathrm{~s}^{-1}$.

$5 \mathrm{~m} \mathrm{~s}^{-1}$, meaning that the increase of the sand impact energy nearly has no influence on the longitudinal growth of the pits.

\section{DISCUSSION}

Results indicate that the FAC and erosion-corrosion behaviour of the EH 32 steel in natural seawater is determined by various factors including mass transfer, fluid hydrodynamics, rust layer, and local chemical and electrochemical environments. The FAC and erosion -corrosion are also dynamic progressions due to the change of the local surface conditions. The transition of the damage pattern from 'flow marks' to pits is directly related to the propagation of FAC and erosion-corrosion in natural seawater. However, most of the previous studies are focussed on the general change of the FAC rate or the general synergistic effect between erosion and corrosion. The interaction of such influencing factors on the localized degradation is difficult to interpret only from the general performance of FAC and erosion-corrosion. Therefore, the localized degradation of steel and the dynamic progression of FAC and erosion-corrosion are further examined and discussed in this work.

It is introduced in the refs. ${ }^{14,25,33}$ that the propagation of 'flow mark' in the flowing $3.5 \mathrm{wt} \% \mathrm{NaCl}$ solution is induced by the anolyte transportation from tip pits to downstream. Similar to the
FAC in $3.5 \mathrm{wt} \% \mathrm{NaCl}$ solution, the loose and porous corrosion products generated in natural seawater at $1 \mathrm{~m} \mathrm{~s}^{-1}$ could not significantly retard the anolyte transportation along the flow direction (Fig. 10a). Accordingly, the long 'flow marks' could also form in the natural seawater at $1 \mathrm{~m} \mathrm{~s}^{-1}$. As shown in Fig. 8a, the sand impacts at $1 \mathrm{~m} \mathrm{~s}^{-1}$ could not remove the corrosion products as well. Meanwhile, the weak sand impacts could not lead to the formation of deep impingement craters at the initial anodic sites (Fig. 10c). Accordingly, the FAC and erosion-corrosion performances are almost the same in the flowing natural seawater at 1 $\mathrm{m} \mathrm{s}^{-1}$.

Pitting damage is the similar feature for both FAC and erosion -corrosion at 3-8 $\mathrm{m} \mathrm{s}^{-1}$. However, it is seen from Fig. $10 \mathrm{~b}$ that the pits are all covered by a large convex layer of corrosion product under FAC. It is totally different from the erosion -corrosion performance that the corrosion products could only be found inside the pits (Fig. 10d). As shown in Fig. 2, a relatively compact $\mathrm{Fe}_{3} \mathrm{O}_{4}$ outer layer could grow and locally cover the steel surface in the natural seawater at $3-8 \mathrm{~m} \mathrm{~s}^{-1}$. Although the outer rust layer formed at $3-8 \mathrm{~m} \mathrm{~s}^{-1}$ is denser than that formed at $1 \mathrm{~m}$ $\mathrm{s}^{-1}$, the electrolyte still could transfer into the underlying surface from the local cracks and peeling. Since the electrolyte is almost stagnant beneath the rust layer, the oxygen diffusion from the 
(a) $1 \mathrm{~m} \mathrm{~s}^{-1}$

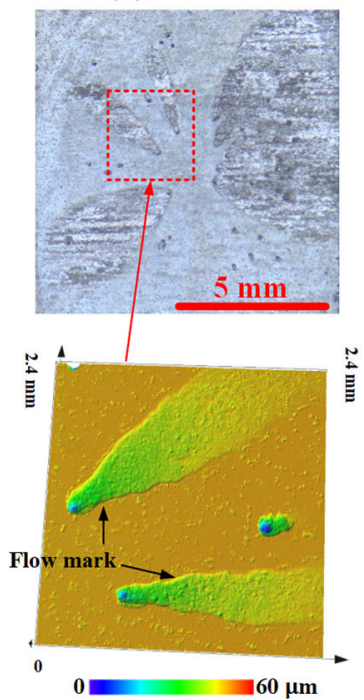

(b) $3 \mathrm{~m} \mathrm{~s}^{-1}$

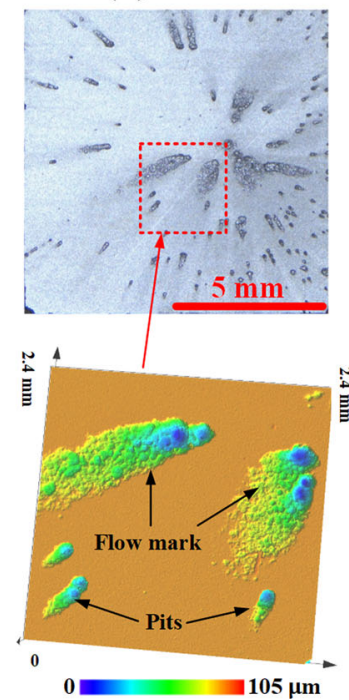

(c) $5 \mathrm{~m} \mathrm{~s}^{-1}$

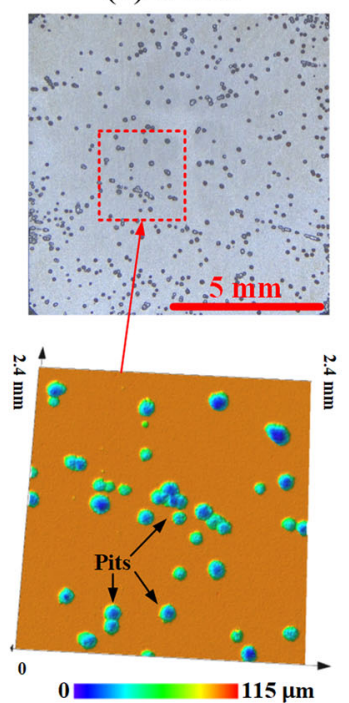

(d) $8 \mathrm{~m} \mathrm{~s}^{-1}$

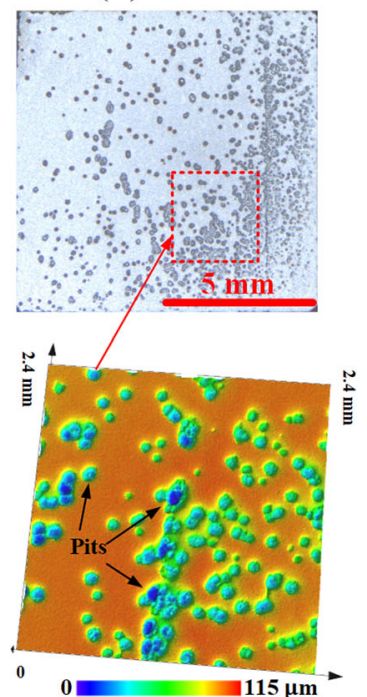

Fig. 9 Photos and local 3D profiles of the steel samples after erosion-corrosion experiments (with rust layer removed) at different flow velocities. a $1 \mathrm{~m} \mathrm{~s}^{-1}, \mathbf{b} 3 \mathrm{~m} \mathrm{~s}^{-1}, \mathbf{c} 5 \mathrm{~m} \mathrm{~s}^{-1}$, and $\mathbf{d ~} 8 \mathrm{~m} \mathrm{~s}^{-1}$.

bulk solution to the steel interface is retarded. The oxygen concentration difference between the rust-covered area and the bare steel area could facilitate the pitting initiation beneath the rust layer ${ }^{6}$. Meanwhile, it is difficult for the generated cations to diffuse from the rust-covered area to the bulk solution (Fig. 10b), leading to the local acidification beneath the rust layer ${ }^{41}$. Thus, the formation of the compact outer layer at $3-8 \mathrm{~m} \mathrm{~s}^{-1}$ could provide an occlusive environment for pitting propagation. When stable pits form beneath the rust layer, the other regions beneath the rust layer would become the major cathodic sites. Due to the inhibition of the oxygen diffusion by the outer rust layer, the enhanced mass transportation only has a slight influence on the cathodic reaction. Accordingly, the FAC rate shows a small increase from 3 to $5 \mathrm{~m} \mathrm{~s}^{-1}$. Along with the $\mathrm{Fe}_{3} \mathrm{O}_{4}$ layer becomes more compact at 5 and $8 \mathrm{~m} \mathrm{~s}^{-1}$, the influence of the oxygen diffusion on the general FAC rate is negligible. However, a more serious pitting corrosion beneath the rust layers might occur in the natural seawater at higher flow velocities.

Unlike the FAC cases, the sand impacts could easily remove the corrosion products from the fine-polished steel surface at $3-8 \mathrm{~m} \mathrm{~s}^{-1}$. The rust layer could not quickly accumulate on the steel surface to provide a warm bed for pitting initiation. The pitting damage under erosion-corrosion is induced by the sand impacts at the local anodic

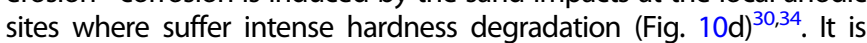
known that the initial crater dimension induced by sand impingements is an important parameter for pitting initiation ${ }^{42}$. The crater needs to reach a certain depth before it could further propagate to a stable pit ${ }^{43}$. It is seen from 3D profile shown in Fig. 6a that the sand impact at $1 \mathrm{~m} \mathrm{~s}^{-1}$ could only slightly deform the steel surface. The shallow crater generated at $1 \mathrm{~m} \mathrm{~s}^{-1}$ is not deep enough for pitting initiation (Fig. 10c). When the flow velocity increases to $3 \mathrm{~m} \mathrm{~s}^{-1}$, the significant increase of the impact energy could lead to the formation of local deep craters at the original anodic sites. These craters would become the incubation sites for pitting initiation. More details of the initiation process of erosion-corrosion pits under active corrosion are introduced elsewhere ${ }^{25,26}$. Along with the impingement craters propagate to stable pits, they provide local sites for corrosion products accumulation. When the impact velocity is between 3 and 5 $\mathrm{m} \mathrm{s}^{-1}$, a relatively compact $\mathrm{Fe}_{3} \mathrm{O}_{4}$ layer could form on the top of the pit as a cover. Although the $\mathrm{Fe}_{3} \mathrm{O}_{4}$ layer is significantly eroded by the sand particles at $8 \mathrm{~m} \mathrm{~s}^{-1}$, the corrosion products are still hard to be totally washed away from the deep pits. The formation of the rust cover could enhance the pitting propagation. However, the rust cover works as a barrier that retards the sand impingements inside the pits. It is seen from Fig. $9 c$, $d$ that the general pit depths are similar at 5 and $8 \mathrm{~m} \mathrm{~s}^{-1}$, indicating that the longitudinal propagation of the pits is mostly induced by corrosion. Erosion could only occur at the edge of the pits, which is obviously seen from the steel debris at the pits boundary. The horizontal expansion of the pits would lead to the formation of new anodic sites at the pits vicinity. Most serious erosion would occur at these local areas due to the reaction between the anolyte and the steel substrate. The intense sand impacts could lead to the steel peel from the steel substrate and fall into the anolyte (Fig. 8h). According to the characterization results, it is investigated that the steel degradation around the pits is induced by the combined effect of erosion and corrosion. However, the longitudinal pitting damage is mostly caused by corrosion due to the accumulation of the corrosion products inside the pit.

Another finding is the variation trends of the corrosion rates during the $12 \mathrm{~h}$ of FAC and erosion-corrosion tests. It is seen that the initial corrosion rate is high in the flowing natural seawater with and without sand particles at a velocity of $1 \mathrm{~m} \mathrm{~s}^{-1}$. The higher corrosion rate at $1 \mathrm{~m} \mathrm{~s}^{-1}$ is induced by the quick propagation of the 'flow marks', leading to the formation of large active areas on the steel surface. Thereafter, the corrosion rate would keep decreasing along with the covering of corrosion products on the steel surface. For the steels suffering pitting corrosion under both FAC and erosion -corrosion conditions, the initial general corrosion rate would be lower than that at $1 \mathrm{~m} \mathrm{~s}^{-1}$. However, the corrosion rate would increase rapidly along with the pits propagation. The results indicate that the quick formation of large anodic areas at low flow rate could lead to a higher initial corrosion rate. The formation of the outer $\mathrm{Fe}_{3} \mathrm{O}_{4}$ and inner $\mathrm{Y}$-FeOOH layer would inhibit the corrosion in a certain extent. But for the pitting corrosion cases, the general corrosion rate would be low during the incubation periods of pitting initiation. Once stable pits form on the steel surface and begin to propagate, the corrosion rate would show an obvious increase. As a result, the variation trends of the corrosion rate in flowing natural seawater might work as an effective indicator for the propagation of localized corrosion.

It is seen Fig. $7 \mathrm{~b}$ that the corrosion rate has a linear relationship with respect to the flow velocity in the sand-entraining flowing seawater, suggesting that the sand impingements could significantly enhance the corrosion process. Since the corrosion 
(a) FAC at $1 \mathrm{~m} \mathrm{~s}^{-1}$
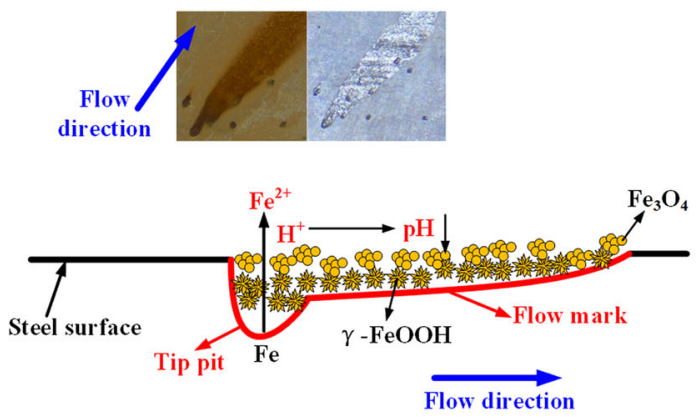

(b) FAC at 3-8 $\mathrm{m} \mathrm{s}^{-1}$
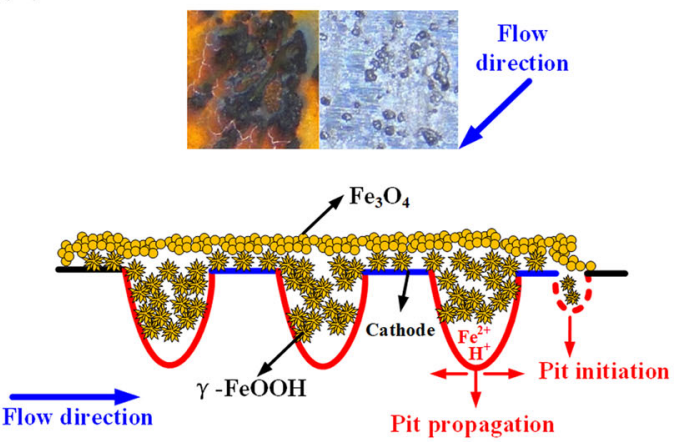

(c) Erosion-corrosion at $1 \mathrm{~m} \mathrm{~s}^{-1}$
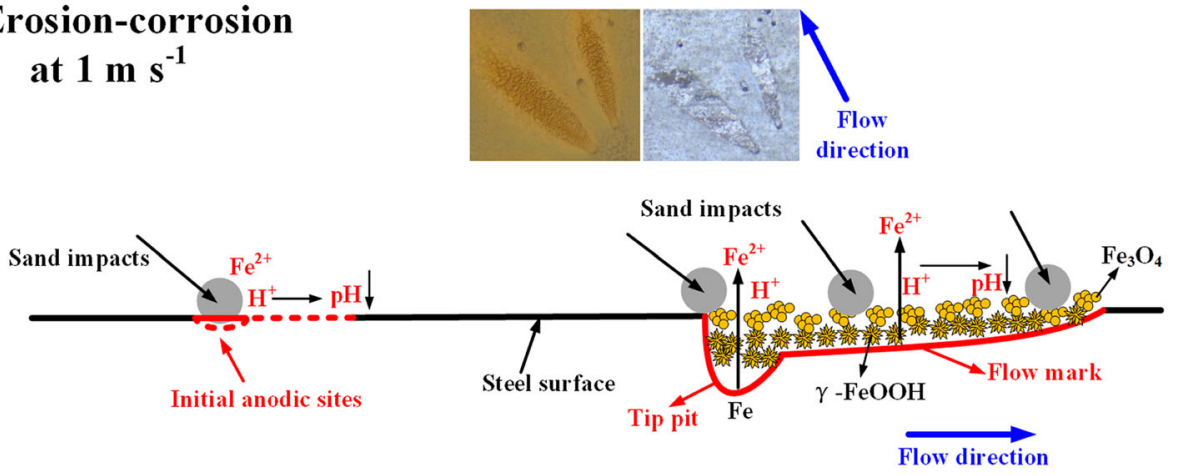

\section{(d) Erosion-corrosion at 3-8 $\mathrm{m} \mathrm{s}^{-1}$}
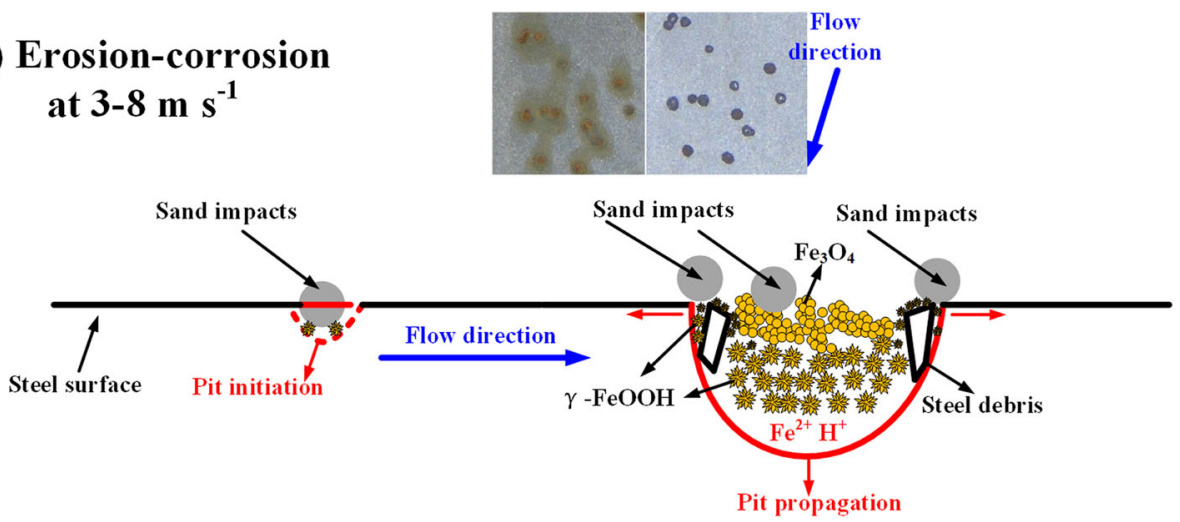

Fig. 10 Schematic diagrams of the propagation of FAC and erosion-corrosion in natural seawater at different flow velocities. a, $b$ The propagation of FAC at $1 \mathrm{~m} \mathrm{~s}^{-1}$ and $3-8 \mathrm{~m} \mathrm{~s}^{-1}$. $\mathbf{c}$, d The propagation of erosion-corrosion at $1 \mathrm{~m} \mathrm{~s}^{-1}$ and $3-8 \mathrm{~m} \mathrm{~s}^{-1}$.

products could not deposit on the pit outside under erosion -corrosion $\left(3-8 \mathrm{~m} \mathrm{~s}^{-1}\right)$, the enhancement of the oxygen diffusion induced by increasing the flow velocity could aggravate the cathodic reaction on the bare steel surface, thus, accelerating the corrosion rate. The persistence of the corrosion rate increase with increasing the flow velocity under erosion-corrosion conditions further verifies that the tiny change of FAC rate in the pure natural seawater is induced by the formation of a relatively compact $\mathrm{Fe}_{3} \mathrm{O}_{4}$ layer. On the other hand, the sand impacts at original anodic sites could facilitate the formation of stable pits. Along with the pitting initiation, the sand impacts at the pit vicinity could lead to the steel substrate peeling from the sample. The peeled steel debris would further dissolve in the anolyte, which could enhance the corrosion process as well. Due to the elimination of the corrosion product and the local acceleration of anodic dissolution at the pit vicinity, the erosion enhanced corrosion is significantly improved to a high level, which counts $60-83 \%$ of the corrosion component at flow velocities of $3-8 \mathrm{~m} \mathrm{~s}^{-1}$.
It is seen from Fig. 6 that micro-cutting and local sand indentations are two major damage patterns for the pure erosion of marine carbon steel in natural seawater. The pure sand impacts could make the steel surface rough. The steel loss induced by pure erosion is negligible in sand containing natural seawater at $1-5 \mathrm{~m} \mathrm{~s}^{-1}$. Along with the occurrence of corrosion, it is found that the erosion steel losses rapidly increase to 2.33 and $3.26 \mathrm{~mm} \mathrm{y}^{-1}$ at 3 and $5 \mathrm{~m} \mathrm{~s}^{-1}$, respectively, which becomes the important contributor to the total steel loss. The erosion steel loss in both cases is mostly induced by the corrosionenhanced erosion. Accordingly, the occurrence of corrosion is the basic requirement for the initiation of significant erosion at 1-5 $\mathrm{m}$ $\mathrm{s}^{-1}$. In combination with the characterization results of the erosion -corrosion performances, it could be deduced that the sand impingements at the initial anodic sites are the main erosion component at the beginning of the test. Along with the formation of stable pits, the sand impingements at the anodic sites of pits boundary become the main reason for erosion. The slight increase of the $\dot{W}_{\mathrm{e}}^{\mathrm{c}}$ from $3.26\left(5 \mathrm{~m} \mathrm{~s}^{-1}\right)$ to $3.69 \mathrm{~mm} \mathrm{y}^{-1}\left(8 \mathrm{~m} \mathrm{~s}^{-1}\right)$ indicates that 


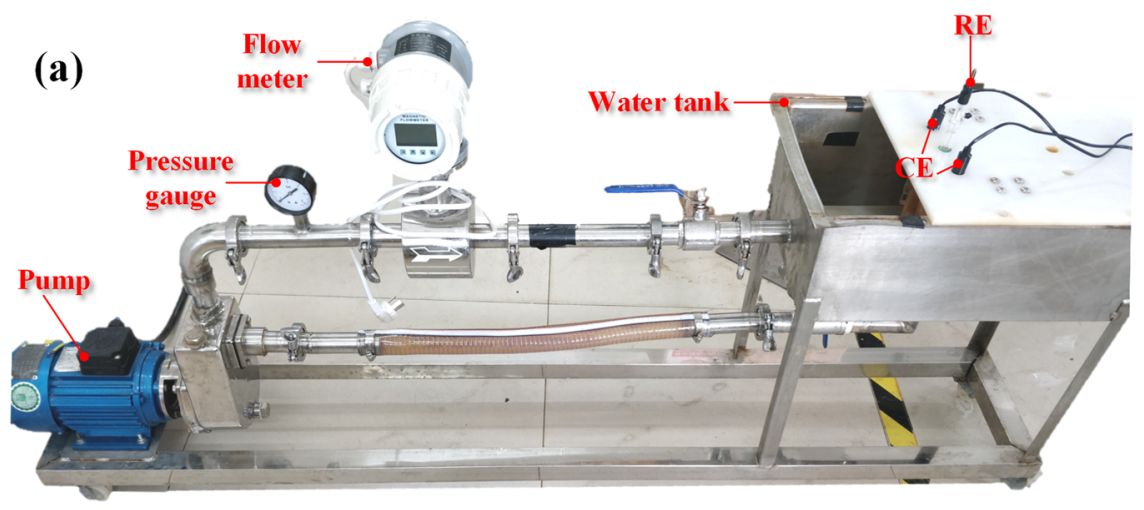

(b)

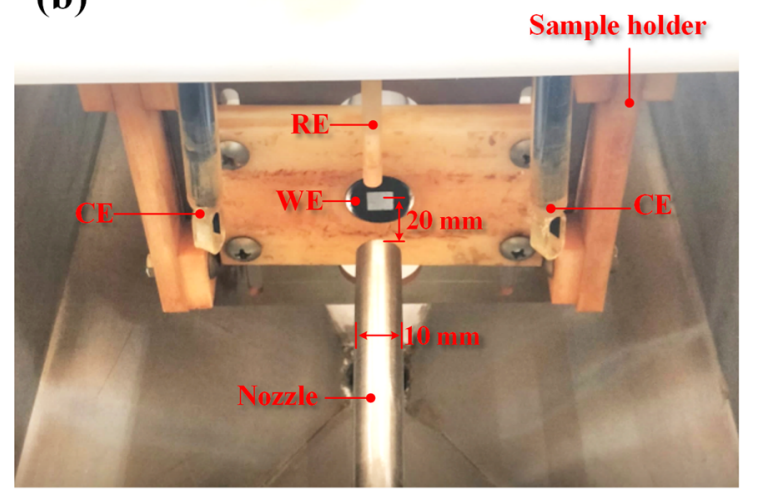

(c)

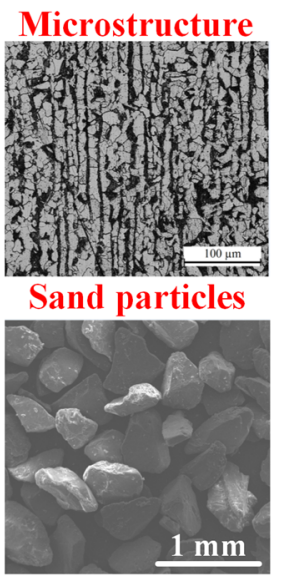

Fig. 11 The jet impingement test setup used for erosion-corrosion experiments and the test materials. a The submerged impingement jet system. b The internal view of the water tank. c The microstructure of the EH 32 carbon steel and the shape of the sand particles.

the corrosion enhanced erosion almost reach the top thread in natural seawater when the flow velocity is higher than $5 \mathrm{~m} \mathrm{~s}^{-1}$.

According to the test results, it is seen that the main factor responsible for the steel degradation at $1 \mathrm{~m} \mathrm{~s}^{-1}$ is corrosion which counts $60 \%$ of the total steel loss. Although the corrosion rates are still slightly higher than the erosion rates at the flow velocities of 3 and $5 \mathrm{~m} \mathrm{~s}^{-1}$, the values of both components are very close, indicating that the steel degradation in these cases is determined by the synergy of erosion and corrosion. However, when the flow velocity further increases to $8 \mathrm{~m} \mathrm{~s}^{-1}$, it is found that the total steel loss induced by erosion reaches $63 \%$ of the total steel loss. This suggests that the steel degradation would gradually change from corrosion-dominated to erosion-dominated with increasing the flow velocity in sand-entraining natural seawater.

In summary, more compact magnetite layers could form on the $\mathrm{EH}$ 32 carbon steel in pure natural seawater at higher flow velocities (3-8 $\mathrm{m} \mathrm{s}^{-1}$ ). The relatively compact rust layer formed at $3-8 \mathrm{~m} \mathrm{~s}^{-1}$ could significantly retard the mass transfer between the bulk solution and the rust-covered area, leading to the formation of local occlusive sites. The inhibition of oxygen diffusion and the accumulation of the corrosive agents beneath the rust layer could facilitate the pitting initiation and propagation. Moreover, the inhibition of the cathodic reaction beneath the rust layer would result in a limited increase of FAC rate with increasing the flow velocity. In sand-entraining natural seawater, the corrosion component is the main contributor to the steel degradation at $1 \mathrm{~m} \mathrm{~s}^{-1}$. The steel degradation is controlled by the synergy of erosion and corrosion at $3-5 \mathrm{~m} \mathrm{~s}^{-1}$. Erosion would become the main contributor to the steel degradation at $8 \mathrm{~m} \mathrm{~s}^{-1}$. The occurrence of corrosion is the basic requirement for the initiation of significant erosion at $1-5 \mathrm{~m} \mathrm{~s}^{-1}$. The increase of the flow velocity from 1 to $5 \mathrm{~m} \mathrm{~s}^{-1}$ could dramatically enhance the erosion process. However, the increment of the corrosion enhanced erosion is relatively small when the flow velocity further increases from 5 to 8 $\mathrm{m} \mathrm{s}^{-1}$. The increase of the sand impact energy could effectively enhance the corrosion process. The erosion enhanced corrosion would become the main contributor to corrosion at $3-8 \mathrm{~m} \mathrm{~s}^{-1}$.

Pitting damage is the main feature of erosion-corrosion in natural seawater of $3-8 \mathrm{~m} \mathrm{~s}^{-1}$. The initiation and propagation of pitting damage are caused by the synergistic effect of local sand impacts and anodic dissolution. The accumulation of corrosion products in the impingement craters would drive the formation of stable pits. However, the accumulated corrosion products could further retard the erosion of pit bottom. The longitudinal growth of the pits is mostly induced by corrosion. The removal of the corrosion product outside the pit by sand impingements could significantly enhance the pitting propagation. The erosion and corrosion could work together at the pit boundary, resulting in the formation of steel debris. Along with the damage pattern changing from 'flow marks' to pits at both FAC and erosion-corrosion conditions, the variation trends of the corrosion rates would transform from decline to rise. The variation trend of the corrosion rate might be used as an indicator for the pitting initiation in flowing natural seawater.

\section{METHODS}

\section{Test setup and materials}

The submerged impingement jet system used for FAC and erosion-corrosion tests is presented in Fig. 11a. The test setup consists of a centrifugal pump, a pressure gauge, a flow meter, and a water tank. The configuration of the unshrouded centrifugal impeller in the pump could allow the sand particles passing through without clogging the pump. The inside view of the water tank is shown in Fig. 11b. The water tank contains a nozzle, a sample holder, a working electrode (WE), a saturated calomel electrode (SCE), and two counter electrodes (CEs). The SCE was used as the reference electrode (RE). The working electrode was made of EH 32 carbon steel which is commonly used to build ships and ocean platforms. The chemical compositions (wt\%) of the EH 32 steel are C 0.12, Si 0.3, Mn 1.32, Cr 0.03, Ni 0.01, Cu 0.02, P 0.016, S 0.003 and 
Fe balance. A copper wire was sticked on the back side of the WE using copper foil tape to make the electrical connection. The WE was mounted in an epoxy resin with an exposed surface of $10 \times 10 \mathrm{~mm}^{2}$. The microstructure of the steel is mainly composed of ferrite and pearlite (as indicated in optical micrograph in Fig. 11c). The inner diameter of the nozzle is $10 \mathrm{~mm}$ and the distance between the nozzle outlet and the WE is $20 \mathrm{~mm}$. The bottom of the tank is constructed by four tilted steel plates, ensuring that sand particles could be recirculated into the flow loop after ejecting from the nozzle outlet.

The natural seawater taken from Bohai Bay (China) was used as the test solution. The main ion contents $\left(\mathrm{g} \mathrm{L}^{-1}\right)$ of the natural seawater are $\mathrm{Cl}^{-} 17.09$, $\mathrm{Na}^{+}$9.45, $\mathrm{SO}_{4}{ }^{2-} 2.20, \mathrm{Mg}^{2+} 1.06, \mathrm{Ca}^{2+} 0.03, \mathrm{~K}^{+} 0.26, \mathrm{HCO}_{3}{ }^{-} 0.13, \mathrm{Br}^{-} 0.03$. The $\mathrm{pH}$ of the natural seawater was measured to around 8.21. The test system was placed in an air-conditioned room, which could maintain the solution temperature at $18 \pm 5^{\circ} \mathrm{C}$ for all tests. Silica sand particles (Fig. 11c) which were sieved by 40 mesh sieve were used for pure erosion and erosion - corrosion tests. The average diameter of the sand particles is around $430 \mu \mathrm{m}$.

\section{FAC tests}

The FAC tests were conducted in pure natural seawater. The WEs were tested at four controlled flow rates of $4.7,14.1,23.6$, and $37.7 \mathrm{~L} \mathrm{~min}^{-1}$, respectively. The average flow velocities $(U)$ of the fluid at the nozzle outlet could be further calculated as:

$$
U=\frac{Q \times 10^{-3}}{15 \pi d^{2}}
$$

where $Q$ is the flow rate, $d$ is the inner diameter of the nozzle $(0.01 \mathrm{~m})$. The calculated average flow velocities are $1,3,5$, and $8 \mathrm{~m} \mathrm{~s}^{-1}$ at each flow rate. The test duration at each flow velocity was $12 \mathrm{~h}$. During the FAC test, the WE, RE, and CEs were connected to a CS 350 electrochemical workstation (CorrTest, Wuhan China) for corrosion rate measurement. The corrosion rate of the WE was measured every $0.5 \mathrm{~h}$ using linear polarization resistance (LPR) method. The potential scanning range of LPR measurement was from -10 to $+10 \mathrm{mV}$ with respect to the open circuit potential. The scanning rate was $0.1 \mathrm{mV} \mathrm{s}^{-1}$. Thereafter, the instant corrosion rate of the WE could be calculated as:

$I_{\text {corr }}=\frac{B}{R_{\mathrm{p}}}$

$\mathrm{CR}=\frac{3.15 \times 10^{5} I_{\text {corr }} M}{A n F \rho}$

where $I_{\text {corr }}$ is the corrosion current, $B$ is the Stern-Geary coefficient which is adopted as $26 \mathrm{mV}$ according to the ref. ${ }^{29,33}, R_{\mathrm{p}}$ is the fitted linear polarization resistance, $C R$ is the instant corrosion rate $\left(\mathrm{mm} \mathrm{y}^{-1}\right), M$ is the molecular weight of iron, $A$ is the surface area of the WE, $n$ is the number of transferred electrons, $F$ is the Faradic constant and $\rho$ is the density of the steel. It is reported that the steel loss induced by fluid shear stress is negligible in natural seawater without sand particles ${ }^{2}$. Accordingly, the average value of the CR during $12 \mathrm{~h}$ of FAC test was deemed as the general pure corrosion rate $\left(\dot{W}_{\mathrm{co}}\right)$ in this work. The FAC tests at each flow velocity were repeated for three times to ensure the repeatability.

After the $12 \mathrm{~h}$ of FAC test, the WE was taken out from the sample holder and immediately photographed by an EOS digital camera (Canon, Tokyo Japan). Then, the compositions and the morphologies of the rust layer formed at different flow velocities were characterized by an inVia Raman spectroscopy (Renishaw, Leeds UK) and an EM-20AX Plus SEM (Coxem, Daejeon Korean). The local compositions of the rust layer were further analysed using EDS analysis. After the characterization of the rust layer, the corrosion products on the WEs were cleaned using the solution suggested in ASTM G1-03. The local 3D profiles of the corroded areas were further examined by an OLS 5000 infinite microscope (Olympus, Tokyo Japan).

\section{Pure erosion tests}

The pure erosion tests were conducted in the natural seawater containing $1 \%$ sand particles (by weight). The WEs were tested at four different fluid flow velocities $\left(1,3,5\right.$, and $\left.8 \mathrm{~m} \mathrm{~s}^{-1}\right)$ and the test duration of each velocity was $12 \mathrm{~h}$. During the pure erosion test, a cathodic potential of $-850 \mathrm{mV}$ (vs. SCE) was applied to WE to prevent the corrosion happen. The pure erosion tests at each flow velocity were repeated for three times to ensure the repeatability.

After the pure erosion test completed, the surface morphology of the WE was examined by the digital camera and further characterized by SEM. Local $3 D$ profiles and the surface roughness of the WEs were also measured by the infinite microscope. The weight loss of the WE induced by pure erosion was measured by an AUW 320 balance (Shimadzu, Kyoto Japan) with an accuracy of $0.01 \mathrm{mg}$. The general pure erosion rate can be calculated as:

$\dot{W}_{\mathrm{e} 0}=\frac{8.76 \times 10^{3} \Delta m}{\rho A \Delta t}$

where $\dot{W}_{\mathrm{e} 0}$ is the pure erosion rate $\left(\mathrm{mm} \mathrm{y}^{-1}\right), \Delta m$ is the measured weight loss and $\Delta t$ is the test duration (12 h).

\section{Erosion-corrosion tests}

The conditions used for erosion-corrosion tests were totally the same as those used for pure erosion tests. The WEs were also tested in the natural seawater containing $1 \mathrm{wt} \%$ sand particles at four different flow velocities $\left(1,3,5\right.$, and $\left.8 \mathrm{~m} \mathrm{~s}^{-1}\right)$ for $12 \mathrm{~h}$. However, no external cathodic potential was applied to the WEs during the erosion-corrosion tests. The WEs were simultaneously subjected to erosion and corrosion. Similar to the FAC tests, the instant corrosion rates of the WEs were measured every $0.5 \mathrm{~h}$ using LPR method. The general corrosion rate $\left(\dot{W}_{c}\right)$ could be calculated from the average value of the $C R$ as well. The erosion-corrosion tests at each flow velocity were repeated for three times to ensure the repeatability.

After the erosion-corrosion tests, the WEs were examined by the digital camera, and the localized erosion-corrosion morphology was characterized by SEM. The generated corrosion products at different flow velocities were analysed by the Raman Spectroscopy and EDS analysis. The local 3D profiles of the WEs were obtained after removing the corrosion products according to ASTM G1-03. Thereafter, the weight losses of the WEs were measured by the balance and the total steel loss rates $\left(\dot{W}_{t}\right)$ at different flow velocities were calculated according to Eq. 5 .

It is known that the total steel loss induced by erosion-corrosion could be expressed as:

$\dot{W}_{\mathrm{t}}=\dot{W}_{\mathrm{c}}+\dot{W}_{\mathrm{e}}=\dot{W}_{\mathrm{c} 0}+\dot{W}_{\mathrm{c}}^{\mathrm{e}}+\dot{W}_{\mathrm{e} 0}+\dot{W}_{\mathrm{e}}^{\mathrm{c}}$

where $\dot{W}_{\mathrm{c}}$ and $\dot{W}_{\mathrm{e}}$ are the corrosion component and erosion component, respectively. $\dot{W}_{\mathrm{co}}$ and $\dot{W}_{\mathrm{e} 0}$ are the pure corrosion rate and pure erosion rate, respectively, which could be obtained from the FAC and pure erosion tests. $\dot{W}_{\mathrm{c}}^{\mathrm{e}}$ and $\dot{W}_{\mathrm{e}}^{\mathrm{c}}$ are the additional steel losses induced by the erosion enhanced corrosion and corrosion enhanced erosion, respectively. The $\dot{W}_{\mathrm{c}}^{\mathrm{e}}$ and $\dot{W}_{\mathrm{e}}^{\mathrm{c}}$ could be calculated and the interaction between erosion and corrosion could be further studied according to the following equations.

$\dot{W}_{\mathrm{c}}^{\mathrm{e}}=\dot{W}_{\mathrm{c}}-\dot{W}_{\mathrm{c} 0}$

$\dot{W}_{\mathrm{e}}^{\mathrm{c}}=\dot{W}_{\mathrm{t}}-\dot{W}_{\mathrm{c}}-\dot{W}_{\mathrm{e} 0}$

Since three identical tests were carried out for each condition, all the components of erosion-corrosion steel loss $\left(\dot{W}_{\mathrm{c} 0}, \dot{W}_{\mathrm{e} 0}, \dot{W}_{\mathrm{c}}, \dot{W}_{\mathrm{e}}, \dot{W}_{\mathrm{c}}^{\mathrm{e}}, \dot{W}_{\mathrm{e}}^{\mathrm{c}}\right)$ presented in this work are the average values of the three repeated tests.

\section{DATA AVAILABILITY}

The data that support the findings of this study are available from the corresponding author upon reasonable request

Received: 26 June 2021; Accepted: 20 October 2021; Published online: 10 November 2021

\section{REFERENCES}

1. Melchers, R. E. Predicting long-term corrosion of metal alloys in physical infrastructure. npj Mater. Degrad. 3, 4 (2019).

2. $\mathrm{Xu}, \mathrm{Y}$. et al. Exploring the corrosion performances of carbon steel in flowing natural sea water and synthetic sea waters. Corros. Eng. Sci. Technol. 55, 579-588 (2020).

3. Ma, H. C., Fan, Y., Liu, Z. Y., Du, C. W. \& Li, X. G. Effect of pre-strain on the electrochemical and stress corrosion cracking behavior of E690 steel in simulated marine atmosphere. Ocean Eng. 182, 188-195 (2019).

4. Hou, B. R. et al. The cost of corrosion in China. npj Mater. Degrad. 1, 4 (2017).

5. Xia, D. et al. Review-material degradation assessed by digital image processing: fundamentals, progresses, and challenges. J. Mater. Sci. Technol. 53, 146-162 (2020).

6. Liu, L., Xu, Y., Zhu, Y., Wang, X. \& Huang, Y. The roles of fluid hydrodynamics, mass transfer, rust layer, and macro-cell current on flow accelerated corrosion of carbon steel in oxygen containing electrolyte. J. Electrochem. Soc. 167, 141510 (2020).

7. López-Ortega, A., Bayón, R. \& Arana, J. L. Evaluation of protective coatings for offshore applications. Corrosion and tribocorrosion behavior in synthetic seawater. Surf. Coat. Technol. 349, 1083-1097 (2018). 
8. Azam, M. A., Sukarti, S. \& Zaimi, M. Corrosion behavior of API-5L-X42 petroleum/ natural gas pipeline steel in South China Sea and Strait of Melaka seawaters. Eng. Fail. Anal. 115, 104654 (2020).

9. Xu, Y. \& Tan, M. Y. Visualising the dynamic processes of flow accelerated corrosion and erosion corrosion using an electrochemically integrated electrode array. Corros. Sci. 139, 438-443 (2018)

10. Seok, W., Park, S. Y. \& Rhee, S. H. An experimental study on the stern bottom pressure distribution of a high-speed planing vessel with and without interceptors. Int. J. Nav. Arch. Ocean. 12, 691-698 (2020).

11. Wang, L. et al. Inhibition on porpoising instability of high-speed planing vessel by ventilated cavity. Appl. Ocean Res. 111, 102688 (2021).

12. Zhang, G. A., Zeng, L., Huang, H. L. \& Guo, X. P. A study of flow accelerated corrosion at elbow of carbon steel pipeline by array electrode and computational fluid dynamics simulation. Corros. Sci. 77, 334-341 (2013).

13. Guo, H. X., Lu, B. T. \& Luo, J. L. Non-Faraday material loss in flowing corrosive solution. Electrochim. Acta 51, 5341-5348 (2006).

14. Wharton, J. A. \& Wood, R. J. K. Influence of flow conditions on the corrosion of AISI 304L stainless steel. Wear 256, 525-536 (2004).

15. Senatore, E. V. et al. Evaluation of high shear inhibitor performance in $\mathrm{CO}_{2}^{-}$ containing flow-induced corrosion and erosion-corrosion environments in the presence and absence of iron carbonate films. Wear 404-405, 143-152 (2018).

16. Kain, V., Roychowdhury, S., Ahmedabadi, P. \& Barua, D. K. Flow accelerated corrosion: experience from examination of components from nuclear power plants. Eng. Fail. Anal. 18, 2028-2041 (2011).

17. Owen, J. et al. An experimental and numerical investigation of $\mathrm{CO}_{2}$ corrosion in a rapid expansion pipe geometry. Corros. Sci. 165, 108362 (2020)

18. Ahmed, W. H., Bello, M. M., El Nakla, M. \& Al Sarkhi, A. Flow and mass transfer downstream of an orifice under flow accelerated corrosion conditions. Nucl. Eng. Des. 252, 52-67 (2012)

19. Liu, F. J., Lin, Y. Z. \& Li, X. Y. Numerical simulation for carbon steel flow-induced corrosion in high-velocity flow seawater. Anti-Corros. Method. Mater. 55, 66-72 (2008).

20. Tang, X., Wang, J. \& Li, Y. Effect of flow velocity of seawater on corrosion rate for A3 steel. Mar. Sci. 29, 26-29 (2005).

21. Choe, S. \& Lee, S. Effect of flow rate on electrochemical characteristics of marine material under seawater environment. Ocean Eng. 141, 18-24 (2017).

22. Xia, J., Li, Z., Jiang, J., Wang, X. \& Zhang, X. Effect of flow rates on erosion -corrosion behavior of hull steel in real seawater. Int. J. Electrochem. Sci. 16, 210532 (2021).

23. $\mathrm{Xu}, \mathrm{Y}$. et al. An overview of major experimental methods and apparatus for measuring and investigating erosion-corrosion of ferrous-based steels. Metals 10, 180 (2020).

24. Jiang, J., Xie, Y., Islam, M. A. \& Stack, M. M. The effect of dissolved oxygen in slurry on erosion-corrosion of En30B steel. J. Bio- Tribo-Corros. 3, 45 (2017).

25. Xu, Y. \& Tan, M. Y. Probing the initiation and propagation processes of flow accelerated corrosion and erosion-corrosion under simulated turbulent flow conditions. Corros. Sci. 151, 163-174 (2019).

26. Xu, Y., Zhang, Q. L., Gao, S., Wang, X. N. \& Huang, Y. Exploring the effects of sand impacts and anodic dissolution on localized erosion-corrosion in sandentraining electrolyte. Wear 478-479, 203907 (2021).

27. Islam, M. A. \& Farhat, Z. Erosion-corrosion mechanism and comparison of erosion-corrosion performance of API steels. Wear 376-377, 533-541 (2017).

28. Wang, Z. B., Zheng, Y. G. \& Yi, J. Z. The role of surface film on the critical flow velocity for erosion-corrosion of pure titanium. Tribol. Int. 133, 67-72 (2019).

29. Xie, J., Alpas, A. T. \& Northwood, D. O. Mechano-electrochemical effect between erosion and corrosion. J. Mater. Sci. 38, 4849-4856 (2003).

30. Guo, H. X., Lu, B. T. \& Luo, J. L. Interaction of mechanical and electrochemical factors in erosion-corrosion of carbon steel. Electrochim. Acta 51, 315-323 (2005).

31. Liu, Y., Zhao, Y. \& Yao, J. Synergistic erosion-corrosion behavior of X80 pipeline steel at various impingement angles in two-phase flow impingement. Wear 466 -467, 203572 (2021).

32. Xu, Y., Liu, L., Zhou, Q., Wang, X. \& Huang, Y. Understanding the influences of precorrosion on the erosion-corrosion performance of pipeline steel. Wear 442 -443, 203151 (2020).

33. $\mathrm{Xu}, \mathrm{Y}$. et al. Electrochemical characteristics of the dynamic progression of erosion -corrosion under different flow conditions and their effects on corrosion rate calculation. J. Solid State Electr. 24, 2511-2524 (2020).

34. Lu, B. T. \& Luo, J. L. Correlation between surface-hardness degradation and erosion resistance of carbon steel-effects of slurry chemistry. Tribol. Int. 83 146-155 (2015).

35. Aminul Islam, M., Farhat, Z. N., Ahmed, E. M. \& Alfantazi, A. M. Erosion enhanced corrosion and corrosion enhanced erosion of API X-70 pipeline steel. Wear 302 1592-1601 (2013).
36. Liu, L., Xu, Y., Xu, C., Wang, X. \& Huang, Y. Detecting and monitoring erosion -corrosion using ring pair electrical resistance sensor in conjunction with electrochemical measurements. Wear 428-429, 328-339 (2019).

37. Yang, Y. \& Cheng, Y. F. Parametric effects on the erosion-corrosion rate and mechanism of carbon steel pipes in oil sands slurry. Wear 276-277, 141-148 (2012)

38. Zeng, L., Zhang, G. A. \& Guo, X. P. Erosion-corrosion at different locations of X65 carbon steel elbow. Corros. Sci. 85, 318-330 (2014).

39. Finnie, I. Some observations on the erosion of ductile metals. Wear 19, 81-90 (1972).

40. Oka, Y. I., Okamura, K. \& Yoshida, T. Practical estimation of erosion damage caused by solid particle impact Part 1: Effects of impact parameters on a predictive equation. Wear 259, 95-101 (2005).

41. Pasha, A., Ghasemi, H. M. \& Neshati, J. Synergistic erosion-corrosion behavior of X-65 carbon steel at various impingement angles. J. Tribol. 139, 011105-1 (2017).

42. Tian, H. et al. Electrochemical corrosion, hydrogen permeation and stress corrosion cracking behavior of E690 steel in thiosulfate-containing artificial seawater. Corros. Sci. 144, 145-162 (2018).

43. Cui, Z. et al. Corrosion behavior of AZ31 magnesium alloy in the chloride solution containing ammonium nitrate. Electrochim. Acta 278, 421-437 (2018).

\section{ACKNOWLEDGEMENTS}

This research is sponsored by China Postdoctoral Science Foundation (2019TQ0049, 2019M661101, 2020M681801), Natural Science Foundation of China (52001055), and Zhejiang Provincial Natural Science Foundation of China (LQ21E090009). We thank Dr. Majid Laleh from Deakin University for his linguistic assistance.

\section{AUTHOR CONTRIBUTIONS}

Y.X.-conceptualization, methodology, investigation, formal analysis, writing-original draft, and funding acquisition. Q.Z.- data collection, formal analysis, writing-review and Editing. Q.Z.-methodology, data collection, formal analysis. S.G.-conceptualization, project administration, resources, and funding acquisition. B.W.-project administration, resources. X.W.-project administration, supervision. Y.H.-conceptualization, supervision, writing-review and editing

\section{COMPETING INTERESTS}

The authors declare no competing interests.

\section{ADDITIONAL INFORMATION}

Supplementary information The online version contains supplementary material available at https://doi.org/10.1038/s41529-021-00205-1.

Correspondence and requests for materials should be addressed to Yunze $\mathrm{Xu}$, Shan Gao or Yi Huang.

Reprints and permission information is available at http://www.nature.com/ reprints

Publisher's note Springer Nature remains neutral with regard to jurisdictional claims in published maps and institutional affiliations.

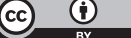

Open Access This article is licensed under a Creative Commons Attribution 4.0 International License, which permits use, sharing, adaptation, distribution and reproduction in any medium or format, as long as you give appropriate credit to the original author(s) and the source, provide a link to the Creative Commons license, and indicate if changes were made. The images or other third party material in this article are included in the article's Creative Commons license, unless indicated otherwise in a credit line to the material. If material is not included in the article's Creative Commons license and your intended use is not permitted by statutory regulation or exceeds the permitted use, you will need to obtain permission directly from the copyright holder. To view a copy of this license, visit http://creativecommons. org/licenses/by/4.0/.

(c) The Author(s) 2021 